\title{
Oxidative stress and regulation of glutathione in lung inflammation
}

\author{
I. Rahman, W. MacNee
}

\begin{abstract}
Oxidative stress and regulation of glutathione in lung inflammation. I. Rahman, W. MacNee. C ERS Journals Ltd 2000.

ABSTRACT: Inflammatory lung diseases are characterized by chronic inflammation and oxidant/antioxidant imbalance, a major cause of cell damage. The development of an oxidant/antioxidant imbalance in lung inflammation may activate redox-sensitive transcription factors such as nuclear factor- $\kappa$ B, and activator protein-1 (AP-1), which regulate the genes for pro-inflammatory mediators and protective antioxidant genes. Glutathione (GSH), a ubiquitous tripeptide thiol, is a vital intra- and extracellular protective antioxidant against oxidative/nitrosative stresses, which plays a key role in the control of pro-inflammatory processes in the lungs. Recent findings have suggested that GSH is important in immune modulation, remodelling of the extracellular matrix, apoptosis and mitochondrial respiration. The rate-limiting enzyme in GSH synthesis is $\gamma$-glutamylcysteine synthetase $(\gamma$-GCS). The human $\gamma$-GCS heavy and light subunits are regulated by AP-1 and antioxidant response elements and are modulated by oxidants, phenolic antioxidants, growth factors, and inflammatory and anti-inflammatory agents in lung cells.

Alterations in alveolar and lung GSH metabolism are widely recognized as a central feature of many inflammatory lung diseases such as idiopathic pulmonary fibrosis, acute respiratory distress syndrome, cystic fibrosis and asthma. The imbalance and/or genetic variation in antioxidant $\gamma$-GCS and pro-inflammatory versus antioxidant genes in response to oxidative stress and inflammation in some individuals may render them more susceptible to lung inflammation. Knowledge of the mechanisms of GSH regulation and balance between the release and expression of pro- and anti-inflammatory mediators could lead to the development of novel therapies based on the pharmacological manipulation of the production as well as gene transfer of this important antioxidant in lung inflammation and injury.

This review describes the redox control and involvement of nuclear factor- $\kappa B$ and activator protein- 1 in the regulation of cellular glutathione and $\gamma$-glutamylcysteine synthetase under conditions of oxidative stress and inflammation, the role of glutathione in oxidant-mediated susceptibility/tolerance, $\gamma$-glutamylcysteine synthetase genetic susceptibility and the potential therapeutic role of glutathione and its precursors in protecting against lung oxidant stress, inflammation and injury.

Eur Respir J 2000; 16: 534-554.
\end{abstract}

Inflammation is an important protective response to cellular/tissue injury. The purpose of this process is to destroy and remove the injurious agent and injured tissues, thereby promoting tissue repair. When this crucial and normally beneficial response occurs in an uncontrolled manner, the result is excessive cellular/tissue damage that results in chronic inflammation and destruction of normal tissue. Reactive oxygen species (ROS), such as the superoxide anion liberated by phagocytes recruited to sites of inflammation, are proposed to be a major cause of the cell and tissue damage, including apoptosis, associated with many chronic inflammatory diseases [1-3]. Lung cells, in particular alveolar epithelial type II cells, are susceptible to the injurious effects of oxidants. It has been shown that lung cells release inflammatory mediators and cytokines/ chemokines such as tumour necrosis factor- $\alpha$ (TNF- $\alpha$ ), interleukin (IL)-1 and IL-8 in response to oxidative/nitro-
Respiratory Medicine Unit, ELEGI \& Colt Laboratories, University of Edinburgh, Medical School, Edinburgh, UK.

Correspondence: I. Rahman

ELEGI Colt Research Laboratories

Wilkie Building

University of Edinburgh

Medical School

Teviot Place

Edinburgh EH8 9AG

UK

Fax: 441316511558

Keywords: Alveolar epithelial cells chronic obstructive pulmonary disease glutathione

inflammation

nuclear factor- $\mathrm{kB}$

oxidants

Received: September 31999

Accepted after revision May 222000

This work was supported by the British Lung Foundation and Rhone PoulencRorer, Dagenham, Kent, UK. sative stress. The release of cytokines/chemokines induces neutrophil recruitment and the activation of key transcription factors such as nuclear factor- $\kappa \mathrm{B}(\mathrm{NF}-\kappa \mathrm{B})$ and activator protein-1 (AP-1), thereby augmenting the inflammatory response and tissue damage $[4,5]$. As a result, the acute and chronic alveolar and/or bronchial inflammatory response is a fundamental process involved in the pathogenesis of many lung diseases such as asthma, chronic obstructive pulmonary disease (COPD), acute respiratory distress syndrome (ARDS), idiopathic pulmonary fibrosis (IPF) and cystic fibrosis (CF). The site and specific characteristics of the inflammatory responses may differ in each of these diseases, but all are characterized by the recruitment to the lungs and activation of inflammatory cells leading to an oxidant/antioxidant imbalance.

Glutathione $(\mathrm{GSH})$ is a tripeptide (L- $\gamma$-glutamyl-L-cysteinyl-glycine) containing a thiol (sulphhydryl) group. GSH 
is an important protective antioxidant against free radicals and other oxidants and has been implicated in immune modulation and inflammatory responses [6-8]. These events include modulation of redox-regulated signal transduction, regulation of cell proliferation, remodelling of the extracellular matrix (ECM), and antiprotease screen, apoptosis and mitochondrial respiration [7-12]. The antioxidant GSH has been shown to be critical to the lungs' antioxidant defences, particularly in protecting airspace epithelium (membrane integrity) from oxidative/free radical (cigarette smoke/air particulates)-mediated injury and inflammation [13-15]. Alterations in the levels of GSH in the lung lining fluid have been shown in various inflammatory conditions. For example GSH levels are decreased in the epithelial lining fluid (ELF) in IPF $[16,17]$, ARDS [18], CF [19], lung allograft [20] and human immunodeficiency virus (HIV)-positive patients [21]. In contrast, total glutathione concentrations, including the oxidized form (GSSG), are higher in the bronchial and alveolar fluid in patients with mild asthma (table 1) [22]. Glutathione is present in increased concentrations in the ELF of chronic smokers, whereas this is not the case in the ELF of acute smokers [23, 24]. However, GSH levels were not decreased in the ELF of IPF and HIV-positive patients who were smokers $[25,26]$. A low GSH concentration in the ELF may contribute to an imbalance between oxidants and antioxidants in the lungs and may amplify inflammatory responses and potentiate lung damage.

It has been suggested that oxidants, antioxidants, and inflammatory and anti-inflammatory agents modulate the activation of redox-sensitive AP-1 and NF- $\kappa$ B [5]. AP-1 and AP-1-like antioxidant response element (ARE) have also been reported to modulate the expression of $\gamma$-glutamylcysteine synthetase ( $\gamma$-GCS), the rate-limiting enzyme in de novo GSH synthesis. $\gamma$-GCS consists of a catalytic heavy subunit ( $\gamma$-GCS-HS) and a regulatory light subunit ( $\gamma$-GCS-LS). It has recently been shown that the promoter $\left(5^{\prime}\right.$-flanking) region of both the human catalytic $\gamma$-GCS-HS and regulatory $\gamma$-GCS-LS genes contain putative AP-1 and ARE response elements which are necessary for $\gamma$-GCS expression in response to diverse stimuli [27-30]. It is possible that differences in ELF glutathione levels in various inflammatory lung diseases

Table 1. - Epithelial lining fluid reduced glutathione (GSH) concentration in inflammatory lung diseases

\begin{tabular}{lccc}
\hline & \multicolumn{2}{c}{ GSH $\mu \mathrm{M}$} & [Ref.] \\
\cline { 2 - 3 } & Controls & Patients & \\
\hline Controls (nonsmokers) & $339 \pm 112$ & - & {$[24]$} \\
Smokers & $544 \pm 97.6$ & - & {$[24]$} \\
Idiopathic pulmonary & $429 \pm 34$ & $97 \pm 18$ & {$[16]$} \\
$\quad$ fibrosis & & & \\
Acute respiratory distress & $651 \pm 103.1$ & $31.5 \pm 8.4$ & {$[18]$} \\
$\quad$ syndrome & & & \\
Lung allograft & $302.6 \pm 40.8$ & $94.0 \pm 9.7$ & {$[20]$} \\
Cystic fibrosis & $257 \pm 21$ & $78 \pm 13$ & {$[19]$} \\
HIV-seropositive & $245 \pm 12$ & $170 \pm 23$ & {$[21]$} \\
Asthma & $23.3 \pm 3^{*}$ & $36.5 \pm 9.4^{*}$ & {$[22]$} \\
\hline
\end{tabular}

*: GSH plus oxidized glutathione (in $\mu \mathrm{M} \cdot \mathrm{mg}$ protein $^{-1}$ ). HIV: human immunodeficiency virus. are due to changes in the molecular regulation of GSH synthesis by AP-1 and ARE activation by oxidants and inflammatory and anti-inflammatory agents, its turnover/ breakdown and/or transport in lung cells. However, the molecular mechanism of glutathione synthesis in lungs of patients with inflammatory lung diseases has not been studied. The imbalance and genetic variability of $\gamma$-GCS and pro-inflammatory gene expression in response to oxidative stress and inflammatory response may be a determinant of susceptibility to lung disease. The aims of this review are: 1) to describe the sources of oxidative stress in inflammation and the redox control of the transcription factors $\mathrm{NF}-\kappa \mathrm{B}$ and $\mathrm{AP}-1$; 2) review the regulation, transport and metabolism of lung cell glutathione and $\gamma$-GCS gene expression in inflammation and oxidative stress; 3 ) discuss the possible role of $\gamma$-GCS versus pro-inflammatory gene imbalance in susceptibility/tolerance; and 4) assess the potential protective and therapeutic role of glutathione and other related thiols in oxidant-induced lung injury and inflammation.

\section{Role of cell-derived oxidants in inflammation}

The presence of oxidative stress in the airspaces and the blood initiates a number of early events during pulmonary inflammation. Inflammatory cells are sequestered into the pulmonary microcirculation and recruited to the airspaces as a result of the generation of mediators such as IL-8. Once recruited, inflammatory cells become activated and generate ROS in response to a sufficient level of a secretagogue stimulus (threshold concentration). The mechanism for this may involve neutrophil adhesion to endothelium and upregulation of CD18 integrins [31, 32], which is known to upregulate the reduced nicotinamide adenine dinucleotide phosphate (NADPH) oxidase hydrogen peroxide-generating system [1]. Activation of macrophages, neutrophils and eosinophils generates $\mathrm{O}_{2} \cdot{ }^{-}$, which is rapidly converted to $\mathrm{H}_{2} \mathrm{O}_{2}$ by superoxide dismutase (SOD), and hydroxyl radicals, formed nonenzymatically in the presence of $\mathrm{Fe}^{2+}$ as a secondary reaction. In neutrophils, myeloperoxidase also catalyses the formation of the potent oxidant hypochlorous acid from $\mathrm{H}_{2} \mathrm{O}_{2}$ in the presence of chloride ions. ROS, which may also be released by lung epithelial cells $[33,34]$ may also stimulate inflammatory cells directly, thereby amplifying lung inflammatory and oxidant events (fig. 1).

ROS are highly reactive and, when generated close to cell membranes, deplete intracellular GSH and oxidize membrane phospholipids (lipid peroxidation), which may continue in a chain reaction. Thus, a single $\cdot \mathrm{OH}$ can result in the formation of many molecules of lipid hydroperoxide in the cell membrane, which may severely disrupt its function and may lead to cell death, or to damage of deoxyribonucleic acid (DNA) in alveolar epithelial cells [35]. ROS and reactive nitrogen species (RNS) also act on certain amino acids in proteins (e.g. enzymes, kinases) such as methionine, tyrosine and cysteine, profoundly altering the function of these proteins in inflammatory lung diseases [36]. Many of the effects of oxidants in airways may be mediated by the secondary release of inflammatory lipid mediators such as 4-hydroxy-2-nonenal, which is known to induce various cellular events 


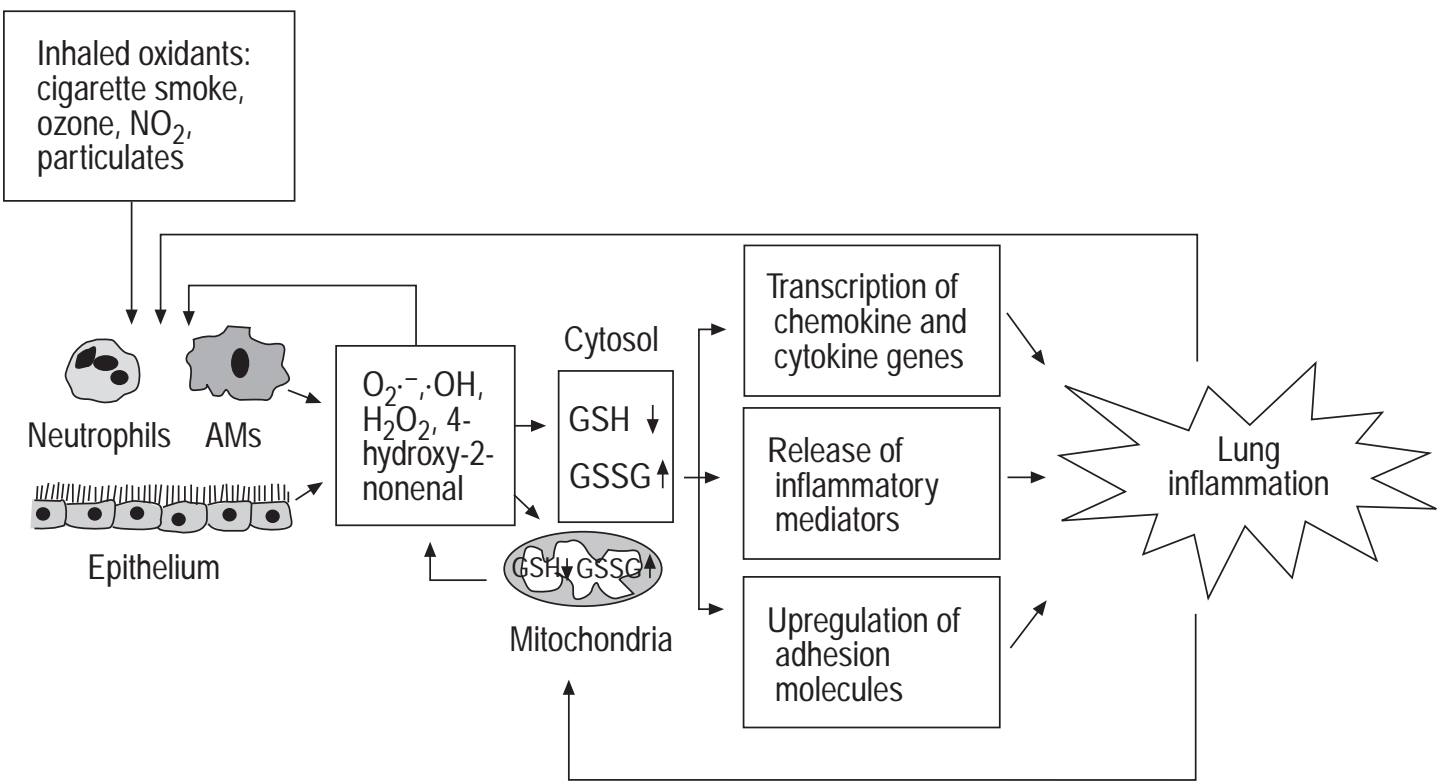

Fig. 1. - Mechanisms of oxidant-mediated lung inflammation. The inflammatory response is mediated by oxidants which are inhaled and/or released by the activated neutrophils, alveolar macrophages (AMs) and epithelial cells leading to depletion of the antioxidant reduced glutathione (GSH). Activation of transcription of the pro-inflammatory cytokine and chemokine genes, upregulation of adhesion molecules and increased release of pro-inflammatory mediators are involved in the inflammatory responses. GSSG: oxidized glutathione; $\downarrow$ : decrease; $\uparrow:$ increase.

such as proliferation and activation of signalling pathways [37].

\section{Inhaled oxidants in lung inflammation}

Inhaled environmental oxidants exacerbate the underlying inflammation in inflammatory lung diseases. Ozone is a potent oxidant, which causes cellular damage by lipid peroxidation as well as loss of functional groups on biomolecules. Inhalation of ozone may lead to an increase in neutrophil numbers, increased airway responsiveness and reduced pulmonary function in normal subjects [38]. This has been linked to neutrophil infiltration into the airway epithelium [39]. Cigarette smoking, another environmental hazard, also delivers oxidants and free radicals to the lungs. Cigarette smoke contains many oxidants and free radicals, both in the gas and the tar phase [40], and causes sequestration of neutrophils into the pulmonary microcirculation and accumulation of macrophages in respiratory bronchioles [41], with the potential to release oxidants $[1,41,42]$. It has been shown recently that the effect of cigarette smoke on acute increases in airway resistance and constriction occurs via a direct oxidant-mediated mechanism [43]. The release of ROS from activated neutrophils in the pulmonary microcirculation has been implicated as a contributor to the inflammatory responses in lung diseases $[1,31]$. Nitrogen dioxide and sulphur dioxide are other inhaled air pollutant oxidants, which may alter lung function by the release of reactive electrophiles and the generation of oxidants [4447]. Inhaled oxidants generated from air pollution particulates (particles with a 50\% cut-off aerodynamic diameter of $10 \mu \mathrm{m}$ (PM10)) are also associated with the release of inflammatory cytokines by airway epithelial cells [48].

\section{Activation of redox-sensitive transcription factors}

\section{Nuclear factor $-\kappa B$}

Oxidants, either inhaled or produced by inflammatory cells, are directly implicated in the inflammatory responses in lung cells via signalling mechanisms. Transcription factors such as NF- $\kappa \mathrm{B}$ and AP-1, which are redox-sensitive $[25,49]$, have been shown to be activated in epithelial cells and inflammatory cells during oxidative stress/ inflammation, leading to the upregulation of a number of pro-inflammatory genes [25]. Maintenance of a high intracellular GSH/GSSG ratio ( $>90 \%)$ minimizes accumulation of disulphides and provides a reducing environment within the cell. However, if oxidant or other environmental stress alters this ratio, this shift in the GSH/GSSG redox buffer influences a variety of cellular signalling processes, such as activation of the transcription factors AP- 1 and NF- $\kappa$ B. Oxidative stress including the presence of lipid peroxidation products [50] or depletion of GSH and subsequent increases in cytosolic GSSG in response to oxidative stress causes rapid ubiquitination and phosphorylation and thus subsequent degradation of the inhibitor of NF- $\kappa \mathrm{B}$ (I $\kappa \mathrm{B})$, which is a critical step for NF- $\kappa \mathrm{B}$ activation $[51,52]$. Under reducing conditions, such as an increase in intracellular GSH following treatment with $N$-acetyl-L-cysteine (NAC), the phosphorylation of serine groups on $\mathrm{I} \kappa \mathrm{B}-\alpha$ following TNF- $\alpha$ treatment is inhibited, leading to the downregulation of NF- $\kappa B$ in endothelial cells (fig. 2) [53].

$\mathrm{NF}-\kappa \mathrm{B}$ regulates the expression of many genes involved in inflammation whose products mediate inflammatory responses in the lungs such as inducible nitric oxide synthase, the pro-inflammatory cytokines IL- $1 \beta$, TNF- $\alpha$ and IL-6, the chemokine IL-8, E-selectin, vascular cell adhesion molecule-1 (VCAM-1), intercellular adhesion molecule-1 (ICAM-1) and granulocyte-macrophage colony-stimulating factor $[4,54,55]$. In many inflammatory 


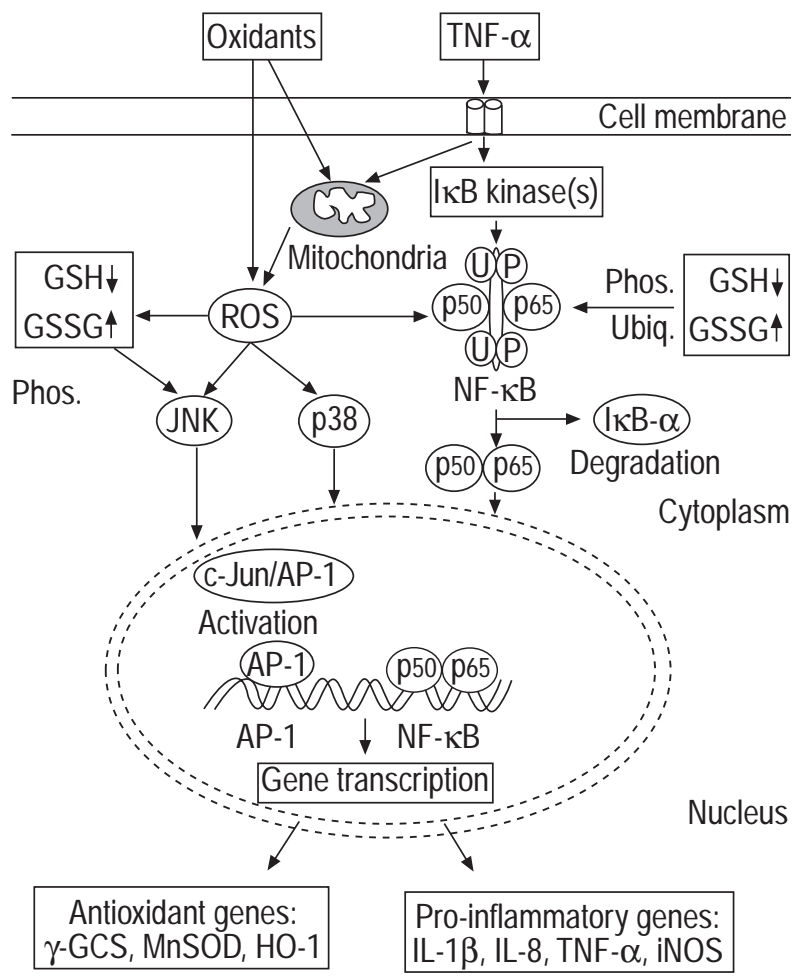

Fig. 2. - Model of the mechanism of nuclear factor- $\kappa \mathrm{B}(\mathrm{NF}-\kappa \mathrm{B})$ and activation protein-1 (AP-1) activation leading to gene transcription in lung epithelial cells. Tumour necrosis factor- $\alpha$ (TNF- $\alpha$ )/oxidants act on mitochondria to generate reactive oxygen species (ROS), which are involved in the activation of NF- $\kappa B$ and AP-1. Activation of NF- $\kappa B$ involves the phosphorylation, ubiquitination and subsequent proteolytic

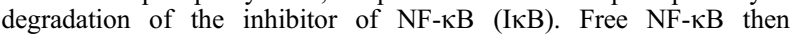
translocates into the nucleus and binds to its consensus sites. The intracellular ratio of reduced glutathione $(\mathrm{GSH}) /$ oxidized glutathione (GSSG) can modulate AP-1 and NF- $\mathrm{BB}$ activation. Similarly, either cJun/c-Jun (homodimer) of c-Fos/c-Jun (heterodimer) is activated by phosphorylation of the c-Jun N-terminal protein kinase (JNK), leading to the activation AP-1, which binds to its tetradecanoylphorbol-13-acetate response element (TRE) consensus regions. Activation of NF- $\mathrm{B} / \mathrm{AP}-1$ leads to the co-ordinate expression of antioxidant protective and proinflammatory genes. $\gamma$-GCS: $\gamma$-glutamylcysteine synthetase; MnSOD: manganese superoxide dismutase; HO-1: haemoxygenase-1; IL: interleukin; iNOS: inducible nitric oxide synthase; $\downarrow:$ decrease; $\uparrow:$ increase. Phos/P: phosphorylation; Ubiq/U: ubiquitination; p38: p38 kinase; p30, p65: NF- $\mathrm{KB}$ subunits.

lung diseases such as IPF, ARDS, CF and HIV, depletion of intracellular GSH levels or increased GSSG levels are present concomitant with the induction of inflammatory mediators and chemotactic cytokines [8]. This suggests that the intracellular redox state (GSH/GSSG levels) of the cell may play a key role in the regulation and potentiation of the inflammatory responses in lung cells.

\section{Activator protein-1}

AP-1 is composed mainly of the Jun and Fos gene products, which form homodimeric (Jun/Jun) or heterodimeric (Jun/Fos) complexes. DNA-binding of the Fos/Jun heterodimer is increased by the reduction of a single conserved cysteine in the DNA-binding domain of each of the proteins [56]. Antioxidants such as NAC increase unstimulated and 12-O-tetradecanoyl-phorbol-13-acetate
(TPA)-stimulated AP-1 DNA-binding and transactivation in HeLa cells [57]. This may be due to conservation of the cysteine (sulphydryl) residue required for the nuclear AP-1 DNA binding. The DNA-binding of AP-1 can be enhanced by thioredoxin as well as the nuclear redox protein, Ref-1, and inhibited by GSSG in many cell types, suggesting that disulphide bond formation by cysteine residues inhibits AP-1 DNA-binding [58, 59]. By contrast, oxidative stress imposed by $\mathrm{H}_{2} \mathrm{O}_{2}$ treatment, depletion of intracellular GSH using DL-buthionine$(S, R)$-sulphoximine (BSO) or an increase in the ratio GSH/GSSG by diamide treatment of the liver cell line HepG2 also stimulates AP-1 binding [60]. This suggests that another mechanism besides direct protein/DNA binding such as redox-sensitive signalling pathways are involved in the regulation of AP-1 activation. This supports work by WILHELM et al. [61] demonstrating that perturbation of cellular thiol redox status provides a signal for AP-1 activation by the induction of stressactivated signal transduction pathways by c-Jun N-terminal protein kinase ( $\mathrm{JNK})$ and $\mathrm{p} 38$ kinase. Moreover, as both oxidants and antioxidants stimulate AP-1, differences in biological responses to these agents are likely to be related to the extent of AP-1 activation and the distinct AP-1 subunits which are upregulated, and hence the response which is provided, since different AP-1 dimers can either stimulate or repress gene expression. In addition, activation of redox-sensitive JNK and p38 by pro-inflammatory cytokines, such as TNF- $\alpha$ and IL-1, leads to the induction of genes for cytokines, chemokines and various pro-inflammatory mediators, which play an important role in the inflammatory response $[5,62,63]$.

\section{Glutathione synthesis and its redox recycling}

The synthesis of glutathione requires the presence of two enzymes and the amino acids, glycine, cysteine and glutamic acid, with cysteine being the rate-limiting substrate. The tripeptide GSH is formed by the consecutive actions of $\gamma$-GCS and glutathione synthetase [64].

In general, the activity of $\gamma$-GCS determines the rate of glutathione synthesis. The reaction, catalysed by $\gamma$-GCS is feedback-inhibited by GSH [64]. The mammalian $\gamma$-GCS holoenzyme is a heterodimer consisting of $\gamma$-GCS-HS (73 $\mathrm{kDa})$ and $\gamma$-GCS-LS (30 kDa) [65]. Although $\gamma$-GCS-HS contains all of the catalytic activity, $\gamma$-GCS activity can be modulated by the association of $\gamma$-GCS-HS with the regulatory $\gamma$-GCS-LS [65]. The regulatory properties of $\gamma$-GCS-LS have been proposed to be mediated by a disulphide bridge between the subunits that would allow conformational changes in the active site depending on the oxidative state of the cell [65]. This implies that potential for increasing the rate of GSH synthesis exists under conditions of GSH depletion.

The GSH redox system is crucial in maintaining intracellular GSH/GSSG homeostasis, which is critical to normal cellular physiological processes, and represents one of the most important antioxidant defence systems in lung cells [64]. This system uses GSH as a substrate in the detoxification of peroxides such as $\mathrm{H}_{2} \mathrm{O}_{2}$ and lipid peroxides, a reaction which involves glutathione peroxidase. This reaction generates GSSG which is then reduced to 
GSH by glutathione reductase in a reaction requiring the hexose monophosphate shunt pathway utilizing NADPH.

\section{Regulation of glutathione and $\gamma$-glutamylcysteine synthetase}

\section{At transcriptional level}

Identification and characterization of the types of diverse stimuli that act as potent inducers of $\gamma$-GCS should aid in the development of effective pharmacological strategies for antioxidant treatment involving GSH regulation in inflammatory lung diseases. To this end, several studies have been directed towards understanding and elucidating the molecular mechanisms of GSH synthesis and regulation in type II alveolar epithelial cells in response to various environmental oxidants, antioxidants and inflammatory stimuli (table 2). The authors' group and other investigators have reported that the promoter $\left(5^{\prime}-\right.$ flanking) region of the human $\gamma$-GCS-HS gene is regulated by a putative c-Jun homodimer (AP-1) binding site

Table 2. - Inducers of glutathione and $\gamma$-glutamylcysteine synthetase

\begin{tabular}{|c|c|}
\hline Agent & [Ref.] \\
\hline \multicolumn{2}{|l|}{ Oxidants } \\
\hline Hydrogen peroxide & {$[30,70]$} \\
\hline Menadione & {$[30,70-72]$} \\
\hline Cigarette smoke & {$[13,29]$} \\
\hline Dimethyl naphthoquinone & {$[73,74]$} \\
\hline Xanthine/xanthine oxidase & {$[71]$} \\
\hline$t$-butyl hydroperoxide and hydroquinone & {$[27,67,68,75]$} \\
\hline 4-Hydroxy-2-nonenal & {$[37,76]$} \\
\hline Ozone & [77] \\
\hline Hyperoxia & {$[71]$} \\
\hline \multicolumn{2}{|l|}{ Phenolic antioxidants } \\
\hline$\beta$-Naphthoflavone & {$[28,78]$} \\
\hline Apocynin & [79] \\
\hline Butylated hydroxyanisole & [80] \\
\hline Butylated hydroxytoluene & [81] \\
\hline Pyrrolidinedithiocarbamate & {$[82,83]$} \\
\hline 5,10 dihydroindeno $(1,2-b)$ indole & [84] \\
\hline \multicolumn{2}{|l|}{ Cytokines } \\
\hline TNF- $\alpha$ & {$[85,86]$} \\
\hline IL-1 $\beta$ & {$[87]$} \\
\hline \multicolumn{2}{|l|}{ Nitric oxide donors } \\
\hline Nitric oxide & {$[88]$} \\
\hline DETA NONOate & [89] \\
\hline$S$-nitrosopenicillamine & [90] \\
\hline \multicolumn{2}{|l|}{ Radiation } \\
\hline Ionizing radiations & {$[91,92]$} \\
\hline \multicolumn{2}{|l|}{ Metals } \\
\hline Selenium & [93] \\
\hline Iron & [94] \\
\hline Cadmium & [95] \\
\hline Mercury & [96] \\
\hline \multicolumn{2}{|l|}{ Chemotherapeutic agents } \\
\hline Cisplatin & {$[66,97]$} \\
\hline Melphalan & [98] \\
\hline \multicolumn{2}{|l|}{ Growth factors } \\
\hline Nerve growth factor & [99] \\
\hline Acid fibroblast growth factor & {$[100]$} \\
\hline \multicolumn{2}{|l|}{ Others } \\
\hline Heat shock & {$[101]$} \\
\hline Oxidized low density lipoprotein & [69] \\
\hline
\end{tabular}

TNF- $\alpha$ : tumour necrosis factor- $\alpha$ IL: interleukin.
[30, 66-69]. The sequence for this binding site is located in the proximal region of the $\gamma$-GCS-HS TATA box in various cell lines, including human alveolar epi-thelial cells $[30,67,68]$.

MulCAHY and coworkers [28, 78], however, have reported a distal ARE containing an embedded TPA-responsive element (TRE) and an electrophile responsive element (or its functional equivalent ARE), which play a key role in the regulation of the $\gamma$-GCS-HS and $\gamma$-GCS-LS, respectively, in response to a planar aromatic xenobiotic, the phenolic antioxidant $\beta$-naphthoflavone, specifically in HepG 2 cells. They also showed that the internal AP- 1 site is important for the constitutive expression of the $\gamma$-GCSLS gene [78]. However, recently, GaLlOWAY and coworkers [27, 75] were unable to demonstrate a role for ARE in the induction of $\gamma$-GCS-LS by oxidants such as $t$ butyl hydroquinone in HepG2 cells. They suggested that an AP-1 site was the critical element for the basal regulation of this subunit. Therefore, it is likely that the expression of the $\gamma$-GCS subunit genes is regulated by different regulatory signals in response to diverse stimuli in specific cells.

Exposure to phenolic antioxidants such as dietary 2(3)-tbutyl-4-hydroxyanisole and butylated hydroxytoluene as well as the synthetic indolic antioxidant 5,10-dihydroindeno(1,2-b) indole and pyrrolidine dithiocarbamate (PDTC), a sulphydryl-modifying antioxidant compound, upregulate $\gamma$-GCS-HS and $\gamma$-GCS-LS in human endothelial cells and other cell lines [75, 80-84]. The plant-derived phenolic antioxidant apocynin (4-hydroxy-3-methoxyacetophenone) also induces GSH synthesis in human alveolar epithelial cells [79]. These effects of phenolic antioxidants are associated with AP-1 transactivation [57, $60,102]$. Therefore, in addition to their scavenging abilities, phenolic antioxidants may provide additional protection from oxidant-induced injury by upregulating the expression of $\gamma$-GCS and increasing GSH levels.

A role for NF- $\kappa$ B in the modulation of $\gamma$-GCS-HS gene expression has also been suggested [91, 103, 104]. It has been shown that blocking the activation of NF- $\kappa B$, which is present at the transcriptional site of the $\gamma$-GCS-HS promoter, by various strategies prevented oxidant/cytokine-induced increase in $\gamma$-GCS-HS transcription in mouse endothelial cells and hepatocytes [91, 103]. However, mutation and deletion techniques applied to the $\gamma$-GCSHS promoter region have ruled out the possible involvement of NF- $\mathrm{BB}$ in the transcriptional upregulation of the $\gamma$-GCS-HS gene in alveolar epithelial cells and other cell lines in response to TNF- $\alpha$ and oxidative stress $[29,30,68,85-87]$.

\section{At post-transcriptional and translational levels}

Regulation of GSH and $\gamma$-GCS has also been described at the post-transcriptional and pretranslational levels in rat liver in vivo and in other cells $[105,106]$. Various inflammatory agents such as cyclic adenosine monophosphate (cAMP) and intracellular calcium, which are released during inflammation, may inhibit GSH synthesis at the translational level (table 3) [107]. It has been shown that $\gamma$-GCS activity is inhibited by agonists of various signal transduction pathways in rat hepatocytes [107], suggesting a role for signalling mechanisms in the 
Table 3. - Inhibitors of glutathione synthesis

\begin{tabular}{lc}
\hline Agent & {$[$ Ref.] } \\
\hline Glucocorticoid (dexamethasone) & {$[71,86]$} \\
Transforming growth factor- $\beta$ & {$[109,110]$} \\
Cyclic adenosine monophosphate & {$[107,108]$} \\
Cytosolic free calcium & {$[107]$} \\
Insulin and hydrocortisone & {$[107]$} \\
Prostaglandin $E_{2}$ & {$[111]$} \\
\hline
\end{tabular}

regulation of GSH levels. Lu et al. [107] reported that hepatic GSH synthesis is downregulated in response to hormones known to mediate their effects through the activation of distinct signal transduction pathways. Using various specific inhibitors of signalling pathways, these investigators determined that hormone-specific inhibition of GSH synthesis was mediated by the activation of protein kinase $\mathrm{A}$, protein kinase $\mathrm{C}$ and $\mathrm{Ca}^{2+} /$ calmodulindependent kinase II. This inhibition of GSH synthesis correlated with the direct phosphorylation of $\gamma$-GCS-HS on serine and threonine residues which was dependent on the concentration of $\mathrm{Mg}^{2+}$. Phosphorylation of $\gamma$-GCSHS was also detected in rat hepatocytes treated with dibutyryl cAMP, resulting in the inhibition of $\gamma$-GCS activity in vivo [108]. Thus, phosphorylation/dephosphorylation may regulate $\gamma$-GCS activity [108] and may provide a mechanism for altering GSH levels in lung cells during oxidative stress.

\section{Role of $\gamma$-glutamyl transpeptidase in the regulation of glutathione levels in lungs}

Modulation of $\gamma$-glutamyl transpeptidase $(\gamma$-GT) may be another avenue for the regulation of intracellular GSH levels in lung cells. $\gamma$-GT cleaves extracellular GSH into its constituent amino acids and leads to the resynthesis of intracellular GSH rather than direct intact cellular GSH uptake [112]. The enzyme $\gamma$-GT is a plasma membrane enzyme, with its active site directed toward the outside of the cell, and is present in lung epithelial cells. This enzyme breaks the $\gamma$-glutamyl bond of $\gamma$-glutamyl-cysteinyl-glycine [113]. The glutamyl moiety is then transferred to an amino acid, a dipeptide or GSH itself, producing its $\gamma$-glutamyl derivative. Thus $\gamma$-GT acts as a salvage enzyme for cellular GSH synthesis. The lung epithelium has been shown to contain high levels of $\gamma$-GT activity and utilizes extracellular GSH from the alveolar lining fluid $[114,115]$. Hence most plasma GSH is catabolized by the enzyme $\gamma$-GT in lungs $[114,115]$. As a result, $\gamma$-GT may be important in determining the levels of GSH in lung ELF. Endothelial cells, alveolar macrophages and fibroblasts have lower $\gamma$-GT levels, and, therefore, less easily use extracellular GSH for intracellular GSH synthesis $[113,115,116]$.

In an animal model, rats exposed to hyperoxia exhibited low $\gamma$-GT activity in ELF; this was associated with low ELF GSH levels [117]. $\gamma$-GT expression is increased in rat lung epithelial cells by oxidants such as menadione and $t$ butyl hydroquinone [118], suggesting that $\gamma$-GT might play a role in protection against oxidative stress. However, cigarette smoke condensate and oxidative stress had no effect on $\gamma$-GT activity in a human type II alveolar epithelial cell lines (A549 cells) [71]. A possible explanation for the differential regulation of $\gamma$-GT activity in response to oxidants may be due to differential expression of the $\gamma$-GT gene in different cell lines and organs and in different species. However, the role of the direct involvement of $\gamma$-GT in the lungs of smokers remains to be proven.

\section{Cystine/cysteine transport and regulation of glutathione levels in lung cells}

The rate-limiting step in the biosynthesis of GSH is the availability of cysteine as a substrate within the cell [64]. Cystine, an oxidized form of cysteine, is efficiently transported in cells by the specific inducible $\mathrm{Na}^{+}$-independent anionic amino acid transport $\mathrm{X}_{\mathrm{c}}{ }^{-}$mechanism and subsequently reduced for use in various metabolic processes including GSH synthesis in lungs [119-122]. Intracellular transport of cystine is accompanied by the extracellular release of glutamate. Cysteine is also transported into cells by sodium-dependent amino acid transport systems (labelled as A or ASC) shared with glutamine and serine [123]. It has been reported that isolated rat alveolar type II cells have a constitutive noninducible $\mathrm{Na}^{+}$-dependent active uptake system that transports exogenous GSH and its $\gamma$-glutamyl analogues into cells against a concentration gradient [124-126]. These transport systems may increase intracellular GSH levels in lung cells, and might be one of the alternative mechanisms modulating intracellular GSH levels in lungs.

Various forms of oxidant stress and $\mathrm{NO}$ also increase the activity of membrane cystine and glutamate transport leading to increased GSH synthesis in lung cells [90, 122, $127,128]$. It has been clearly shown that the cystine uptake is the rate-limiting step for GSH synthesis in cultured lung cells, especially under conditions of oxidative stress [66, 129]. Oxidants (hyperoxia and $\mathrm{H}_{2} \mathrm{O}_{2}$ ), and agents such as sodium arsenite, cadmium, electrophilic compounds and diethyl maleate, also induce cystine transport in various lung cells, macrophages and erythrocytes that is analogous to the $\mathrm{X}_{\mathrm{c}}^{-}$-transport system, a sodium-independent inducible system specific to the intracellular transport of cystine and glutamate [130-133]. It has been shown that exposure of rats to hyperoxia results in increases in total lung GSH within $24 \mathrm{~h}[6,134]$. It is, therefore, possible that induction of cystine or cysteine transport could contribute to the increased GSH levels in lungs after exposure to hyperoxia $[6,134]$.

The regulation of cystine/glutamate transport is governed by the availability of extracellular cysteine or cystine as well as the extracellular redox state (which is, in part determined by extracellular GSH levels) [120, 135]. Treatment with reducing agents such as NAC or GSH increases intracellular GSH levels by making intracellular cysteine available and reducing cystine to cysteine in bovine pulmonary artery endothelial cells [121]. Furthermore, NAC increases intracellular GSH levels in bovine pulmonary artery endothelial cells even in the absence of cystine in the medium [135]. This suggests that a different transport mechanism independent of the $\mathrm{X}_{\mathrm{c}}{ }^{-}$system may be involved in type II epithelial cells in increasing GSH levels in response to various stresses [125]. Nevertheless, this is one of the mechanisms whereby lung cells increase 
intracellular GSH levels under various stresses (either oxidant stress or GSH depletion).

The levels of intracellular GSH are regulated, in part, by the rate of the bidirectional membrane transport system present in lung and liver cells $[136,137]$. It is likely that this membrane transport system causes GSH to efflux to the lung ELF. The function of such a GSH transport system is influenced by the redox/thiol status of the cell, the membrane potential and presence of cations in the extracellular environment [138, 139]. GSH-related structural compounds, such as glutathione-S-conjugates and GSH ethyl ester, inhibit cellular GSH uptake or influx [137, 138]. Furthermore, a more oxidized extracellular environment stimulates cells to retain $\mathrm{GSH}$, whereas a more reduced extracellular state facilitates GSH efflux $[137,140]$. However, these effects are in direct contrast with the situation in lungs in vivo, since the increased oxidant burden imposed by smoking and endogenous oxidative stress during inflammation could cause lung cells to retain GSH, rather than release it into the ELF. This mechanism is difficult to explain in the presence of such a bidirectional GSH transporter in the lung. Thus the mechanisms that determine the levels of GSH in the lung ELF using the bidirectional transporter are not fully understood.

\section{Regulation of glutathione in oxidant-mediated susceptibility/tolerance}

\section{Effect of pro- and anti-inflammatory mediators}

TNF- $\alpha$ is a ubiquitous pro-inflammatory cytokine and is recognized as an important mediator of inflammatory events in the lungs. It induces chronic inflammatory changes associated with an increase in a variety of defence mechanisms including antioxidants levels [141]. TNF- $\alpha$ is an important inflammatory mediator in COPD and ARDS and is present in increased amounts in the bronchoalveolar lavage fluid (BALF) and sputum of COPD patients [142]. Recently, various investigators [86, 143] have shown rapid depletion of intracellular GSH by TNF- $\alpha$ exposure in epithelial and endothelial cells in vitro, due to oxidation of GSH to GSSG. This is followed by a rebound increase in GSH levels in epithelial and endothelial cells as an adaptive response to oxidant stress, occurring as a result of upregulation of the $\gamma$-GCS-HS and activation of AP-1 [85, 87]. Similarly, exposure of fibroblasts to prostaglandin $\mathrm{E}_{2}$, an inflammatory mediator capable of regulating fibroblast cell proliferation and matrix protein production, resulted in decreased GSH synthesis [111]. Furthermore, GSH concentrations in peripheral blood lymphocytes may be decreased as a result of lung inflammation and may be inversely correlated with lung function in patients with CF [144]. Thus oxidative stress imposed by inflammatory mediators may acutely deplete GSH during inflammation and render cells susceptible to the amplification of inflammatory responses.

Glucocorticoids, such as dexamethasone, are widely used as anti-inflammatory agents in various inflammatory lung diseases. Airway epithelium is one of the most important targets for inhaled glucocorticoids in lung diseases [145]. Exposure of lung epithelial A549 cells to de- xamethasone decreases both basal and stimulated GSH levels (TNF- $\alpha$-treated) in these cells $[71,86]$. Dexamethasone also decreases $\gamma$-GCS-HS gene expression in alveolar epithelial cells in vitro by a transcriptional mechanism involving inhibition of the AP-1 transcription factor [86]. Thus it is possible that the use of dexamethasone in patients with inflammatory lung diseases may prevent synthesis of the protective antioxidant GSH.

\section{Effects of oxidants}

Exposure of alveolar epithelial cells in vitro to oxidants, such as $\mathrm{H}_{2} \mathrm{O}_{2}$, hyperoxia and redox recycling compounds like menadione, causes an initial depletion of $\mathrm{GSH}$, associated with increased formation of GSSG, followed by a rebound increase in GSH levels at $24 \mathrm{~h}[29,70-72]$. This is concomitant with increased expression of messenger ribonucleic acid (mRNA) for the $\gamma$-GCS gene [30, 70, 72]. Epithelial cells also take up glutathione by a redox-dependent mechanism [137]. This transport system may act to regulate intracellular glutathione depending on the presence of reduced thiols or disulphides in the extracellular environment [138]. Thus, the short-term effects of various oxidants and oxidant-generating systems appear to be to upregulate the gene for glutathione synthesis, possibly providing a protective/adaptive mechanism against subsequent oxidative stress (table 2).

Oxidative stress produced by ozone [77], xanthine/ xanthine oxidase [71], lipid peroxidation products (4hydroxy-2-nonenal) [76], ionizing radiation [91, 92], hypoxia [146] and heat shock [101] all lead to short-term falls in intracellular GSH levels, followed by increases in GSH levels or upregulation of $\gamma$-GCS-HS mRNA in alveolar epithelial cells, endothelial cells in vitro and other cell types as well as in vivo in rats. NO and its donors, such as $S$-nitrosopenicillamine or DetaNONOate, also cause transient depletion of GSH followed by induction of GSH synthesis by enhanced expression of the $\gamma$-GCS-HS and $\gamma$-GCS-LS in rat aortic vascular smooth muscle cells [90], pulmonary fibroblasts [89] and bovine aortic endothelial cells [88]. The increase in GSH levels caused by NO donors is a further potential mechanism for protecting cells against oxidative stress and subsequent inflammation. Oxidative stress imposed by heavy metals such as selenium [93], iron [94], methyl mercury [96], and cadmium [95] also induce GSH synthesis in various organs in both rats and mice. Other cytotoxic compounds that act through the generation of ROS such as the chemotherapeutic agents cisplatin [66, 97] and melphalan [98] also increase GSH synthesis in cancer cell lines. These drugs may also coinduce the multidrug resistance-associated protein (MRP) gene and the adenosine triphosphate-dependent transporter, glutathione-conjugate (GS-X) pump, in lung cells [147150]. The functional role of MRP coexpression in lung cells is currently unknown. It is possible that the coexpression of MRP and GS-X is related to protection against the inflammatory response and detoxification of xenobiotics and endogenous cysteinyl leukotrienes [151]. The induction of GSH synthesis may be associated with activation of mitogen-activated protein kinases, particularly c-JNK, in response to oxidants, heavy metals and NO [37]. $\gamma$-GCS-LS is also concomitantly induced in 
response to oxidants and phenolic antioxidants in rat lung epithelial L2 cells and liver HepG2 cells, suggesting that concomitant induction of both subunits may be a potential mechanism for enhancing cellular GSH synthesis, and so developing cellular tolerance to oxidative stress [28, 73]. Exposure to sublethal doses of oxidants and oxidantgenerating systems may initiate an adaptive intracellular antioxidant response, thus protecting cells from subsequent exposures to oxidant stresses [74, 152]. It is possible that the GSH synthesis and tolerance mechanism which occurs in response to various stimuli described in various cells may differ in lung cells.

\section{Effect of growth factors}

Transforming growth factor (TGF)- $\beta 1$ is a multifunctional growth factor that modulates cellular proliferation and induces differentiation and synthesis of extracellular matrix proteins, including collagens and fibronectin, in many types of lung cell [153]. Recent studies have shown increased expression of TGF- $\beta 1$ in bronchiolar and alveolar epithelium in IPF and COPD patients, and higher levels in the BALF of atopic asthmatics as compared to healthy subjects $[154,155]$. TGF- $\beta 1$ also downregulates $\gamma$-GCS-HS mRNA and glutathione synthesis in human alveolar epithelial cells and pulmonary artery endothelial cells in vitro $[109,110]$. Interestingly, recent studies by FACTOR et al. [156] showed decreased glutathione synthesis in a TGF transgenic (overexpression) mouse model and increased susceptibility to oxidant-mediated injury. Various workers have shown that $\gamma$-GCS-HS mRNA expression is under the control of the AP-1 transcription factor $[31,67,68,86]$, and that TGF- $\beta 1$ may decrease $\gamma$-GCS-HS gene expression via an AP-1 mechanism [157]. Thus higher levels of TGF- $\beta 1$ may downregulate glutathione synthesis in the lungs of patients with inflammatory diseases such as IPF and COPD. Moreover, decreased GSH levels may also have direct functional consequences. In vitro studies showed that GSH (in the concentration range normally found in ELF) suppressed fibroblast proliferation [158]. The relevance of GSH regulation and subsequent tolerance/ susceptibility in lung epithelial cells in response to pro-/ anti-inflammatory mediators and/or oxidants under conditions of chronic inflammation in vivo is not known.

Differential regulation of glutathione and $\gamma$-GCS gene expression have been demonstrated by other growth factors such as nerve growth factor [99] and plating cells at a low cell density $[103,159,160]$. Intracellular GSH levels have also been shown to be elevated in response to mitogenic stimulation as cells exit from their quiescent state and conditions that lead to cellular transformation [161-165]. Extracellular acid fibroblast growth factor (FGF-1) has been demonstrated to cause transformation and aggressive cell growth in murine embryonic fibroblasts. Recent data from CHOI et al. [100] have shown that expression of a chimeric human FGF-1 gene containing a signal peptide sequence for secretion (hst/ KSOFGF-1) in an embryonic fibroblast cell line caused increased gene expression of both $\gamma$-GCS subunits associated with increased $\gamma$-GCS activity without elevation of intracellular GSH levels [100]. They suggested that an increase in GSH content per se is not required for altered cell growth though increased expression of $\gamma$-GCS and $\gamma$-GCS activity is associated with a common response to growth factors.

\section{Role of $\gamma$-glutamylcysteine synthetase in genetic susceptibility to disease}

Recent studies have shown that GSH regulation/the GSH redox system might be one of the factors involved in genetic susceptibility to oxidant-/pollutant-mediated lung cell damage. For example genetic susceptibility to cigarette smoke has been suggested as a risk factor for the development of COPD [166, 167]. Furthermore, it has been shown that polymorphic expression of several different xenogenes, including those encoding cytochrome P-450 1A1 (CYP1A1), glutathione-S-transferases (GSTs) (GSTM1 and GST-pi) and microsomal epoxide hydrolase, as well as pro-inflammatory genes such as TNF- $\alpha$, is associated with an increased risk of chronic inflammatory lung diseases [168-172] and inflammatory response [173, 174]. The expression of these genes is directly or indirectly related to the modulation of enzymes of the glutathione redox system and $\gamma$-GCS $[85-87,102,166]$. Variations in the expression of the $\gamma$-GCS gene in humans may represent a new susceptibility factor in oxidantinduced injury, which is thought to occur as part of the pathogenesis in COPD. It has been proposed that a GAG trinucleotide repeat polymorphism occurs in the $5^{\prime}$-coding and noncoding regions of the $\gamma$-GCS-HS gene [175]. Genetic analysis of 50 unrelated Caucasians identified three alleles as follows: A1 (nine repeats, 35\% frequency), A2 (eight repeats, $11 \%$ frequency), and A3 (seven repeats, $54 \%$ frequency). Although certain trinucleotide repeats have been associated with recombinatory events, the functional significance of this particular allelic polymorphism, if any, is unknown. Depletion of GSH levels has been associated with a genetic polymorphism and deficiency of $\gamma$-GCS activity in a patient with haemolytic anaemia [176]. Genetic analysis revealed that the $\gamma$-GCS polymorphism was associated with an A to T mutation/ transversion at nucleotide 1109 that predicted substitution of histidine with leucine at amino acid 370, a diallelic polymorphism in nucleotide +206 of an intron and another polymorphism that consisted of a duplication of CAGC at complementary DNA (cDNA) nucleotides 1972-1975 in the $3^{\prime}$-untranslated region of the $\gamma$-GCS catalytic subunit. This mutation was not present in the $\gamma-$ GCS DNA of 38 healthy subjects [176]. The presence of such mutation and possibly associated genetic polymorphism in the coding and/or noncoding region of the $\gamma$ GCS catalytic/regulatory subunit might be associated with the depletion of GSH in the inflammatory response and susceptibility to chronic inflammatory diseases.

The $\gamma$-GCS subunit genes are located on separate chromosomes and expression of their mRNA varies considerably between different tissues [175, 177, 178]. Human $\gamma$-GCS-HS is located on chromosome $6(6 \mathrm{p} 12)$ and $\gamma$-GCS-LS on chromosome 1 (1p21) [177-179]. Genetic analysis reveals that a frequent deletion of the $\gamma$-GCS-LS chromosome, $1 \mathrm{p} 22 \rightarrow \mathrm{p} 21$, occurs in human malignant mesothelioma. This gene deletion is considered to predispose an individual to the development of mesothelioma [180]. Recent data have demonstrated that AP-1 and ARE, which are present in the promoter region of the 
$\gamma$-GCS-HS and $\gamma$-GCS-LS genes, may be directly involved in the regulation of GSH in human cells $[28,30$, $75,78]$. Within a population, it is likely that there will be variation (gene deletion or mutation) in the $5^{\prime}$-coding/ noncoding regions of $\gamma$-GCS-HS and $\gamma$-GCS-LS genes. Future studies need to be directed towards understanding the nature of any polymorphisms that exist and whether any association exists between these polymorphisms and susceptibility to the development of inflammatory lung diseases such as COPD and IPF.

\section{Role of glutathione in the regulation of pro- inflammatory and antioxidant protective genes}

There is increasing evidence to suggest that many inflammatory lung diseases are associated with airway/ airspace inflammation and/or oxidant/antioxidant imbalance leading to alteration in glutathione levels in the ELF. It is also well documented that many pro-inflammatory and antioxidant genes are regulated by a redox-dependent signalling mechanism in lung cells. Hence critical regulation of intracellular glutathione levels under oxidative stress and inflammation might determine the expression of proinflammatory and antioxidant genes. Therefore, it is likely that both redox GSH levels and the various forms of oxidative stress (ROS)/nitrosative stress would determine the regulation of specific genes for pro-inflammatory mediators and antioxidant enzymes.

\section{Pro-inflammatory genes}

Inflammatory mediators play a crucial role in chronic inflammatory processes and appear to determine the nature of the inflammatory response by directing the selective recruitment and activation of inflammatory cells and their perpetuation within the lungs. In in vitro studies, using macrophages and alveolar and bronchial epithelial cells, oxidants (ROS) have been shown to cause both the release of inflammatory mediators such as IL-8, IL-1 and NO and increased expression of pro-inflammatory genes via alteration in redox GSH-dependent mechanisms [181183]. The genes for these inflammatory mediators are

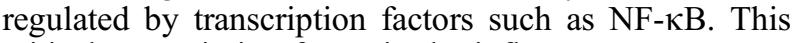
critical transcription factor in the inflammatory response is redox-sensitive. It is also known that various forms of nitrosative stress (reactive nitrogen intermediates/RNS or NO donors) have an effect on intracellular lung GSH levels leading to the expression of various pro-inflammatory mediators such as TGF- $\beta 1$ and activation of nuclear enzymes such as poly (adenosine diphosphateribose) synthetase, which is involved in inflammation [184-186].

The modulation of intracellular thiol status not only quenches oxidants/free radicals but also buffers the antioxidant potential of the cell and detoxifies electrophilic compounds. Thiol antioxidants such as NAC and $N$-acystelyn (lysine salt of $\mathrm{N}$-acetyl-L-cysteine), which have potential as therapies in inflammatory diseases, have been shown, in in vitro and in vivo experiments, to block the release of these inflammatory mediators from epithelial cells and macrophages by a mechanism involving increasing intracellular GSH levels and decreasing NF- $\mathrm{KB}$ activation [182, 183, 187].

\section{Antioxidant protective genes}

An important effect of oxidative stress and inflammation is the upregulation of protective antioxidant genes (fig. 3). Among the antioxidant enzymes, GSH and its redox enzymes appear to play an important protective role in the airspaces and intracellularly in epithelial cells. The protective role of GSH against the effects of cigarette smoke/ oxidants has been demonstrated both in vivo in the rat and in vitro using monolayer cultures of alveolar epithelial cells $[13,14,188]$. Acute intratracheal instillation of cigarette smoke condensate in the rat and exposure of epithelial cell monolayers to cigarette smoke in vitro [13] lead to a profound decrease in GSH levels in BALF, and in the lungs of rats and epithelial cells. This is followed by a rebound adaptive increase in GSH levels and $\gamma$-GCSHS mRNA expression in both rat lungs and epithelial cell lines $[13,189]$. This finding is mirrored in humans, in whom GSH levels are elevated in ELF associated with increased expression of $\gamma$-GCS mRNA in the lungs of chronic cigarette smokers, whereas this is not the case in acute smoking compared to nonsmokers [23, 24, 190]. Thus oxidative stress, including that produced by cigarette smoking, causes upregulation of an important gene involved in the synthesis of GSH as an adaptive mechanism against subsequent oxidative stress. However, this adaptive response may not counteract the potential burden of pro-inflammatory mediators and oxidants released during inflammation.

A recent study has shown that expression of $\gamma$-GCS mRNA is elevated in smokers' lungs and that this is even more pronounced in smokers with COPD [190]. This implies that GSH synthesis might be upregulated (GSH levels were not studied) in the lungs of smokers with and without COPD. Similarly, rats exposed to cigarette smoke have shown increased expression of genes encoding manganese SOD (MnSOD), metallothionein and glutathione peroxidase (GPx) in bronchial epithelial cells, suggesting the importance of the antioxidant gene adaptive response against the injurious effects of cigarette smoke [191]. Important protective antioxidant genes such as those encoding MnSOD, $\gamma$-GCS-HS, haem oxygenase1 (HO-1), GPx, thioredoxin reductase and metallothionein are induced by modulation of cellular GSH/GSSG

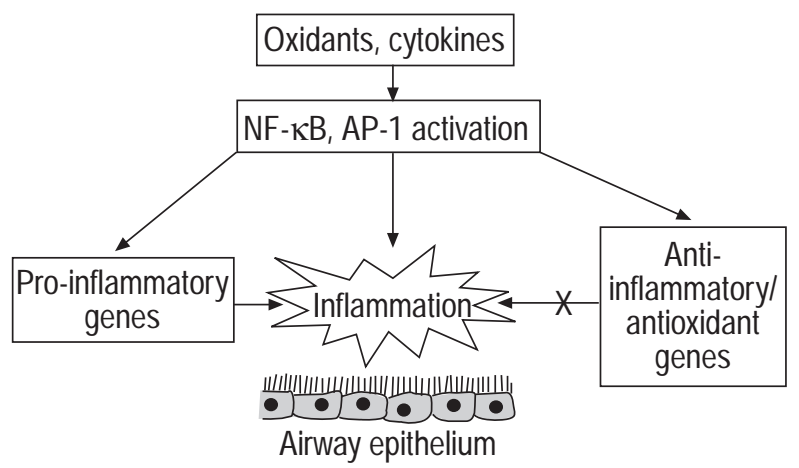

Fig. 3. - Activation of the transcription factors nuclear factor- $\kappa \mathrm{B}(\mathrm{NF}-$ $\kappa \mathrm{B})$ and activation protein-1 (AP-1) by oxidants and/or pro-inflammatory cytokines leads to the induction of both pro-inflammatory and anti-inflammatory/antioxidant genes in lung cells. Products of proinflammatory genes cause airway inflammation, which is inhibited (X) by anti-inflammatory and/or antioxidant genes. 
levels in response to various oxidative stresses including hyperoxia and inflammatory mediators such as TNF- $\alpha$ and lipopolysaccharide in lung cells $[85,86,141,192$, 193].

Thus oxidative/nitrosative stresses, including redox modulation, cause increased gene expression of proinflammatory genes via oxidant-mediated activation of transcription factors such as AP-1 and NF- $\kappa \mathrm{B}$ and also activation of stress response protective genes such as $\gamma$ GCS-HS, HO-1 and MnSOD in lungs. A balance may therefore exist between pro- and anti-inflammatory gene expression and the levels of GSH in response to oxidative stress and during inflammation, which may be critical to whether this leads to cell injury or protection against the injurious effects of inflammation (fig. 4). Knowledge of the molecular mechanisms that sequentially regulate this battery of genes in relation to GSH levels in lung cells may open new therapeutic avenues in the modulation of inflammatory responses in lung diseases.

\section{Protective role of glutathione in oxidant and free radical-mediated lung injury}

Alveolar epithelial cells are important in maintaining the integrity and fluid balance of the lungs. The epithelium lining the airways and alveoli has a protective barrier function. The lower respiratory tract is sensitive to injury from inhaled and locally produced oxidants. In response to injury, the epithelium loses its selective permeability and becomes more permeable to the movement of water, ions and macromolecules. Increased epithelial permeability is one of the earliest events in lung injury and may enhance the inflammatory process by allowing easier access for

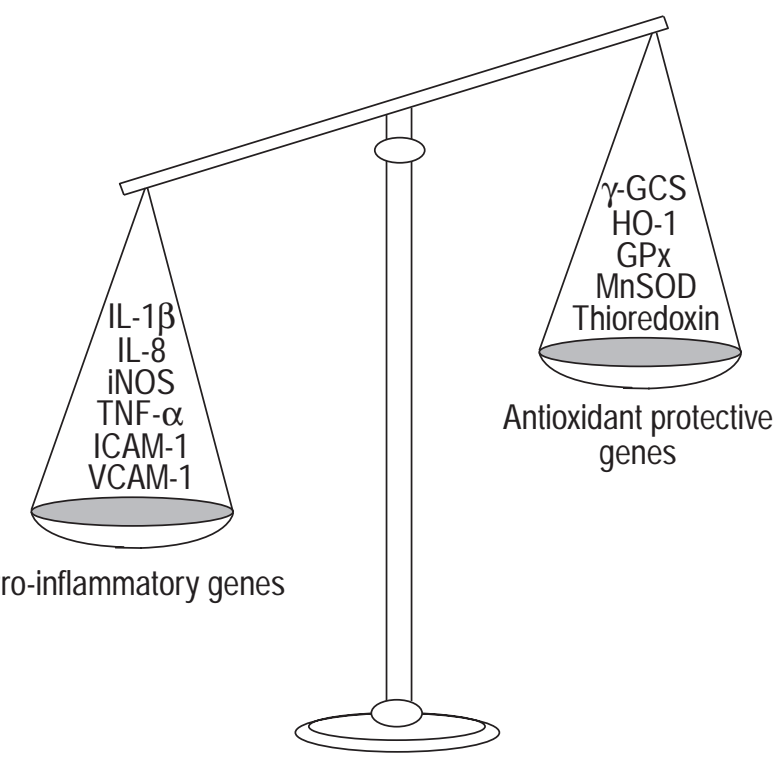

Fig. 4. - Pro-inflammatory and antioxidant protective gene imbalance in inflammation. In inflammation, the balance appears to be tipped in favour of increased pro-inflammatory mediators, due to either release of inflammatory mediators or amplification of the pro-inflammatory effects. Induction of antioxidant protective genes may be a delayed response and decline sharply. IL: interleukin; iNOS: inducible nitric oxide synthase; TNF- $\alpha$ : tumour necrosis factor- $\alpha$; ICAM-1: intercellular adhesion molecule-1; VCAM-1: vascular cell adhesion molecule-1; $\gamma$ GCS: $\gamma$-glutamylcysteine synthetase; HO-1: haem oxygenase-1; GPx: glutathione peroxidase; MnSOD: manganese superoxide dismutase. inflammatory and injurious mediators between the blood, interstitium and alveolar space.

\section{Cigarette smoke/air particulate-mediated lung injury}

Alveolar cells are normally covered in a thin protective layer of epithelial fluid, which is rich in antioxidants such as GSH [194]. It has been reported that incubation with extracellular GSH and increasing intracellular GSH levels protect against oxidant stress in alveolar type II cells [7, 195]. In addition, extracellular GPx, which has been described recently [196], is secreted into ELF by alveolar epithelial cells and macrophages and may provide further defence against oxidants [196]. Following acute inflammation and oxidative stress, the ELF may become depleted of antioxidants such as GSH, increasing the potential for damage to the underlying epithelial cells. Both in vivo and in vitro in monolayers of cultured epithelial cells, this decrease in GSH was associated with an increase in airspace epithelial permeability $[13,14$, 188]. Decreasing GSH levels in both these in vivo and in vitro models using the $\gamma$-GCS inhibitor BSO produces increased epithelial permeability [13]. NisHIKAWA et al. [197] recently demonstrated that acute cigarette smoke exposure, in guinea-pigs, produced neutrophil influx into the airways associated with NF- $\mathrm{BB}$ activation and IL-8 mRNA expression in alveolar macrophages. This may be due to GSH depletion of lung and alveolar macrophages by cigarette smoke. Furthermore, Li et al. [198] reported that instillation of air particulate matter (PM10) into the lungs of rats caused inflammation, decreases in lung GSH levels and increases in epithelial permeability. Oxidative stress and inflammation in response to air particulates have been shown to be prevented by NAC treatment in alveolar epithelial cells [48, 199]. Similarly, other air pollution gases such as $\mathrm{SO}_{2}$ and $\mathrm{NO}_{2}$ produce an inflammatory response and alveolar permeability via depletion of lung GSH levels in rats and A549 epithelial cells [44, 200, 201]. The decrease in GSH levels was associated with inhibition of several enzymes involved in the GSH redox system and glutathione synthesis, and the production of lipid peroxidation products in rat lungs and human alveolar epithelial cells [46, 200, 202, 203]. These studies suggest that GSH plays a critical role in maintaining epithelial membrane integrity and may protect epithelial cells against the inflammatory response produced by either inhaled or endogenous oxidants/free radicals. Furthermore, LINDEN and coworkers [204, 205] demonstrated that airway obstruction, measured by means of the forced expiratory volume in one second (FEV1) in patients with COPD, correlated significantly with the concentration of GSH in BALF; the higher the BALF GSH, the lower the FEV1. It may be that the BALF GSH levels were influenced by the recent smoking history of these patients [24].

\section{Against inflammatory events in lungs}

Neutrophil/endothelial interactions are events necessary for the progression of inflammatory responses in lung diseases. Recently, it has been shown that changes in endothelial cell GSH/GSSG ratio produce expression of different adhesion molecules on the cell surface, which are 
associated with enhanced neutrophil/endothelial adhesion [206]. Agents that cause oxidation of GSH led to increases in neutrophil adhesion to endothelial cells via upregulation of ICAM-1 and VCAM-1 [207, 208], and increasing intracellular thiol concentrations with NAC attenuated the oxidant- or cytokine-mediated neutrophil adhesion to endothelial cells [208]. Therefore, a change in intracellular GSH redox balance may be an important mechanism in neutrophil adhesion, which is involved in chronic lung inflammation.

Modulation of growth factor receptors and altered cellular signalling is proposed to occur through a redoxmediated mechanism in inflammatory and lung cells. Tyrosine phosphorylation of the epidermal growth factor (EGF) receptor in lung epithelial cells by $\mathrm{H}_{2} \mathrm{O}_{2}$ is thought to influence inflammatory processes in lungs [209]. $\mathrm{H}_{2} \mathrm{O}_{2}$ is known to induce apoptosis in many cells including epithelial cells, and this response is inhibited by glutathione $[3,9,210,211]$. In addition, a decrease in intracellular GSH levels in alveolar macrophages caused by oxidants, hyperoxia and cigarette smoke produces downregulation of vascular endothelial growth factor (VEGF) and its functional receptor [212, 213]. Downregulation of VEGF and its receptor may be associated with apoptosis, which may be linked in the pathogenesis of inflammatory lung diseases such as emphysema and COPD. GSH and other thiols such as NAC inhibit TNF$\alpha$-induced sphingomyelin hydrolysis, ceramide generation and programmed cell death (apoptosis), suggesting that GSH has antiapoptotic properties through its ability to detoxify oxidants and free radicals [214].

$\mathrm{HO}-1$ is a member of the heat shock family of proteins, which plays an important role in inflammation. A role for $\mathrm{GSH}$ in the regulation of heat shock factor and activation of heat shock protein has been suggested [215]. The intracellular levels of GSH in fibroblasts modulate oxidant-induced expression of HO-1 [216]. This effect was due to the direct involvement of AP-1 (Jun/Jun) binding [192]. Similarly, metal-induced expression of the heat shock protein gene $h s p 72$ is attenuated by glutathione, implying a protective role of GSH in acute inflammation [217]. Hence, it is clear that maintenance of intracellular GSH levels is important in the control of inflammatory responses in lungs involving heat shock proteins.

\section{Oxidant-mediated mitochondrial damage}

Mitochondria normally produce a substantial quantity of ROS (e.g. $\mathrm{H}_{2} \mathrm{O}_{2}$ and $\mathrm{O}_{2} \cdot{ }^{-}$), which are normally broken down by GSH-dependent peroxidase-catalysed reactions. Mitochondria contain $15-20 \%$ of the total cellular GSH. The mitochondrial GSH pool is derived solely from the activity of a mitochondrial transporter that translocates GSH from the cytosol into the mitochondrial matrix, as mitochondria do not possess the enzymes $\gamma$-GCS or $\gamma$-GT [218]. Mitochondrial GSH may also be susceptible to the oxidative stress imposed by TNF- $\alpha$, and inhaled or endogenous oxidants in human lungs $[10,219]$. TNF- $\alpha$ is known to deplete cytosolic GSH levels transiently in lung epithelial and endothelial cells [86, 143, 220]. This depletion by TNF- $\alpha$ is thought to be due to oxidative stress from mitochondrial leakage of $\mathrm{O}_{2} \cdot{ }^{-}$via the electron transport chain $[143,221]$. Oxidation of GSH is associ- ated with activation of NF- $\kappa \mathrm{B}$ and damage to mitochondrial DNA leading to apoptosis in fibroblasts in vitro and a decline in lung function in smokers [219, 221, 222]. It is likely that mitochondrial GSH plays a key role in maintaining cellular antioxidant defence systems, and thus cell integrity and function, under various conditions of oxidative stress [221, 223]. CHEN et al. [220] have recently demonstrated that depletion of mitochondrial GSH in human umbilical vein endothelial cells (HUVECs) increased TNF- $\alpha$-induced adhesion molecule (VCAM-1) expression but not ICAM-1 expression and mononuclear leukocyte adhesion in HUVECs, suggesting that mitochondrial GSH is involved in endothelial cell function [220]. Recent studies have shown that gene delivery of glutathione reductase to mitochondria and overexpression of GPx in various cell lines provided protection against oxidative stress [224, 225]. This finding demonstrates the importance of mitochondrial GSH homeostasis in the regulation of cell function. It is possible that an imbalance in mitochondrial GSH redox status may help to perpetuate inflammation in lung cells.

\section{Oxidant-mediated extracellular matrix remodelling}

Intracellular redox GSH levels have been shown to be involved in the remodelling of ECM during oxidantmediated lung injury [226, 227]. This is supported by two observations: 1) oxidant-induced lung injury was attenuated by the synthetic matrix metalloproteinase (MMP) inhibitor British Biotech (BB)-3103 [228]; and 2) depletion of intracellular GSH was associated with activation of MMPs, thereby increasing degradation of the alveolar ECM in lungs [227]. This breakdown of lung ECM by MMP-9 and MMP-2 activation was blocked by increasing lung glutathione levels [227]. It has been shown that oxidative stress imposed by ozone decreases lung glutathione levels associated with altered ECM protein type I collagen gene expression [229]. Other forms of oxidative stress which are derived from $t$-butyl hydroperoxide and iron could also modify collagen synthesis, by a mechanism presumably involving a redox sensor/ receptor $[226,230]$. TYagi and coworkers $[11,226]$ demonstrated that in vitro exposure of normal myocardium to GSSG leads to the activation of MMPs, which was associated with oxidation of the active cysteine residue present on MMPs. GSSG also inhibited tissue inhibitor of metalloproteinase (TIMP) in fibroblasts [226]. Thiol antioxidants such as GSH and NAC and the phenolic antioxidant PDTC have been shown to inhibit the activation of MMP-2 and MMP-1 associated with increased TIMP levels in cultured fibroblast cells [220].

\section{Immune effector response}

The recent findings of PETERSON et al. [231] regarding the importance of GSH levels in antigen-presenting cells in modulating T-helper (Th) cell 1 versus Th2 cytokine response patterns in immune responses to the nature of the antigen, and the decreased intracellular levels of GSH in peripheral blood lymphocytes of CF and HIV-seropositive patients $[144,232]$, led to the assumption that this important tripeptide thiol may be involved in the 
functional regulation of the immune response. However, the impact of chronic GSH depletion in T-cells, B-cells, macrophages and neutrophils in immune/inflammatory lung diseases have not been studied so far. Chronic depletion of GSH may be coupled with immunodeficiency and poor survival, as evidenced in the CD4 T-cells of HIV-seropositive patients [8, 21, 232, 233]. Intracellular redox GSH levels in these immune/inflammatory cells may also effect signal transduction and activation of transcription factors and lead to elevated gene expression (e.g. of IL-8 and IL-4) [8, 234]. GSH deficiency also leads to T-cell inactivation and apoptosis $[235,236]$. More research is necessary to understand the mechanism/ involvement of redox GSH levels and the regulation of glutathione synthesis in the regulation of the immune response.

\section{Protective role of thiol compounds in inflammation}

NAC, a cysteine-donating compound, acts as a cellular precursor of GSH and on deacetylation becomes cysteine. It reduces disulphide bonds, but also has the potential to interact directly with oxidants. NAC is also used as a mucolytic agent (to reduce mucus viscosity and improve mucociliary clearance) [237]. NAC has been used in an attempt to enhance lung GSH levels and reduce inflammation in patients with COPD and IPF with variable success [238-241]. Oral treatment with NAC (200 mg three times daily for 8 weeks) in healthy chronic cigarette smokers reduced inflammation and lowered BALF levels of eosinophilic cationic protein, lactoferrin, antichymotrypsin and chemotactic activity for neutrophils [242].

In some cases, NAC might cause elevation of the antioxidant screen in lung ELF, as shown in patients with IPF, in whom NAC caused significantly elevated GSH levels in alveolar lavage fluid [241]. This may provide therapeutic effects on the rate and extent of the development of fibrotic lesions in these patients. Indeed, oral administration of $600 \mathrm{mg}$ NAC three times daily for 12 weeks to patients with IPF improved lung function in these patients [243]. Intravenous NAC treatment for $72 \mathrm{~h}$ improved systemic oxygenation and reduced the need for ventilatory support in patients with mild-to-moderate acute lung injury but failed to influence the development of the condition, or its mortality [244]. In a prospective randomized double-blind placebo-controlled study, administration of NAC $\left(150 \mathrm{mg} \cdot \mathrm{kg}^{-1}\right.$ bolus, followed by a continuous infusion of $50 \mathrm{mg} \cdot \mathrm{kg}^{-1}$ over $4 \mathrm{~h}$ ) led to decreased IL-8 levels without any change in plasma TNF$\alpha$, IL-6 or IL-10 levels in patients with septic shock [245]. This anti-inflammatory effect of NAC was associated with improved oxygenation and static lung compliance in these patients, suggesting that NAC may be used as an adjunctive treatment in patients with septic shock [245]. In an in vitro study, NAC was shown to inhibit neutrophil and monocyte chemotaxis and the respiratory burst [246]. Animal studies have suggested that NAC produces deleterious effects on the lung epithelium in response to hyperoxia exposure [247]. Furthermore, a direct link between these clinical effects (i.e. reductions in the number of exacerbations and in the decline in lung function and inflammation) and the efficacy of NAC as an in vivo antioxidant has not been convincingly established to date $[1,13]$.

NAL, a lysine salt of $N$-acetyl-L-cysteine, is a mucolytic and antioxidant thiol compound. The advantage of NAL over NAC is that it has a neutral $\mathrm{pH}$ in solution, whereas NAC is acidic. NAL can be aerosolized into the lung without causing significant side-effects [248]. GILLISSEN et al. [248] compared the effects of NAL and NAC and found that both drugs enhanced intracellular glutathione levels in alveolar epithelial cells and inhibited $\mathrm{H}_{2} \mathrm{O}_{2}$ and $\mathrm{O}_{2} \cdot{ }^{-}$release from human blood-derived polymorphonuclear neutrophils (PMNs) from smokers with COPD. NAL also inhibited ROS generation induced by serumopsonized zymosan by human PMNs. This inhibitory response was comparable to the effects of NAC [249]. Therefore, NAL may represent an interesting alternative approach to augmenting the antioxidant screen in the lungs.

Certain other thiol-releasing agents such as glutathione ethyl ester and L-thiozolidine-4-carboxylate are potentially useful compounds for cysteine/glutathione delivery [250, 251]. However, studies are needed to validate the bioavailability of these compounds in lung inflammation.

\section{Glutathione therapeutic perspectives in inflammatory lung diseases}

The evidence is overwhelming that glutathione plays a vital role in cellular modulation of the inflammatory response, antioxidant capability, antiprotease system, immune effectiveness, remodelling of the ECM, surfactant/ phosphatidylcholine and mucolysis. It is clear that ELF GSH levels are decreased in various inflammatory lung diseases. Thus increasing lung cellular levels of the GSH/ antioxidant screen would be a logical approach in inflammatory lung diseases. Extracellular augmentation of GSH has been attempted through intravenous administration of GSH, oral ingestion of GSH and inhalation of nebulized GSH [252-260] in an attempt to reduce inflammation in lung diseases [261] such as in IPF [253], mild asthmatics [254] and CF [255, 256]. GSH aerosol therapy normalized low GSH levels in the lungs of these patients [253-256]; however, nebulized GSH also had a detrimental effect in asthmatic patients by producing bronchoconstriction, presumably due to the formation of GSSG [254]. This suggests that GSH aerosol therapy may not be an appropriate means of increasing GSH levels in lung ELF and cells in patients with asthma. GSH aerosols also increased the formation of GSSG in patients with IPF [253] but suppressed lung epithelial surface inflammatory cell-derived oxidants in patients with $\mathrm{CF}$. Recent data have indicated that the low levels of ELF/apical fluid $\mathrm{GSH}$ in patients with $\mathrm{CF}$ is attributable to abnormal GSH transport (inability to bring out GSH efflux), which might be associated with a missing or defective CF transmembrane conductance regulator channel, through which efflux of organic anions normally occurs [262, 263]. The depletion of lung GSH may be reflected in peripheral blood lymphocytes in these patients [144]. It may be feasible to use a GSH aerosol to restore the oxidant/ antioxidant imbalance in these patients $[256,259]$. In all of these studies, questions were raised as to the bioavailability of GSH, the $\mathrm{pH}$ and osmolality at the site of 
the microenvironment and the resultant formation of deleterious products (GSSG). It seems rational to suggest that neutralizing the $\mathrm{pH}$, providing GSH in salt form, using liposome-entrapped GSH delivery and maintenance of isotonicity would be useful in designing any GSH inhalation therapy in inflammatory lung diseases.

Increasing the activity of $\gamma$-GCS and glutathione synthetase by gene transfer techniques may increase cellular GSH levels. Transfection of cDNAs for the heavy and light subunits of human $\gamma$-GCS-HS resulted in elevation of intracellular glutathione levels in COS-7 cells [264]. These cells were thereafter resistant to chemotherapeutic drugs. Similarly, MANNA et al. [265] have recently demonstrated that overexpression of $\gamma$-GCS in rat hepatoma cells completely protected against the TNF- $\alpha$-induced activation of NF- $\mathrm{\kappa B}, \mathrm{AP}-1$, stress-activated protein kinase/JNK and apoptosis. They highlighted the importance of glutathione and $\gamma$-GCS in protecting against the cytotoxic effects of various agents and that most of the actions of TNF- $\alpha$ are regulated by the glutathione-controlled redox status of the cell. Modulation of GSH synthesis in organs such as the skeletal muscle of critically ill patients, in whom GSH synthesis is markedly affected, would be another means of targeting GSH synthesis by gene transfer $[259,266]$. Thus the induction of $\gamma$-GCS by molecular means to increase cellular GSH levels or $\gamma$-GCS gene therapy holds great promise in protection against chronic inflammation and oxidant-mediated injury in various inflammatory diseases.

\section{Conclusions and future directions}

ROS and RNS are generated by several inflammatory and immune and various structural cells of the airways. An imbalance of oxidant/antioxidant in favour of oxidants contributes to the pathogenesis of several inflammatory lung diseases. GSH is an important protective antioxidant in the lungs, the levels of which are altered in the ELF in several of these conditions. Glutathione and $\gamma$-GCS are regulated by oxidants, phenolic antioxidants, pro-inflammatory mediators and anti-inflammatory agents and growth factors in lung cells. In addition, intracellular and extracellular GSH levels are also regulated by cystine/ cysteine transport mechanisms and by $\gamma$-GT. $\gamma$-GCS is regulated at both transcriptional (AP-1, ARE and NF- $\mathrm{kB}$ ) and translational levels. Although the molecular mechanism of $\gamma$-GCS activity is well characterized, its regulation in response to specific stimuli in particular inflammatory lung diseases has not been studied. More work should be carried out to address this regulation using human tissue.

Regulation of intracellular redox GSH levels in response to ROS/RNS and in inflammation should have critical effects, in different lung cells, on the activation of redox sensor/signal transduction pathways and various transcription factors such as NF- $\mathrm{KB}$ and AP-1. The regulation of intracellular glutathione levels may determine the balance between expression of pro-inflammatory mediators and antioxidant genes. Imbalance of redox-regulated proinflammatory and antioxidant genes in response to inflammatory mediators, oxidants and growth factors might be associated with susceptibility/tolerance to disease. Modern technologies such as DNA array and differential display might be utilized in detecting and assessing the novel target genes involved in disease susceptibility. The polymorphism in the $\gamma$-GCS gene may be associated with initiation/exacerbation of inflammation as a result of a mutation in this critical antioxidant gene. Hence, studies must be directed at detecting the existence, if any, of such genetic polymorphisms in susceptible/nonsusceptible populations and patients with inflammatory lung diseases.

Study of the protective role of reduced glutathione/thiol compounds in inhibition of the inflammatory response (activation of nuclear factor- $\mathrm{\kappa} \mathrm{B} /$ inhibitor of nuclear factor$\mathrm{\kappa B}$ kinases) and correcting the fundamental oxidant/antioxidant imbalance in patients with chronic inflammatory diseases are important areas of further research. Augmentation of intra- and extracellular levels of glutathione and related thiols via aerosolization/inhalation and $\gamma$-glutamylcysteine synthetase by gene transfer in lungs will not only enhance the protective antioxidant potential but may also inhibit oxidant-mediated acute and chronic inflammatory responses. Understanding of the cellular and molecular redox-regulating mechanisms in inflammation is needed to design antioxidant therapeutic strategies for the treatment of various inflammatory lung conditions.

Acknowledgements. The authors thank L.A. Jimenez and P. Gilmour for their useful comments during revision of the manuscript.

\section{References}

1. Rahman I, MacNee W. Role of oxidants/antioxidants in smoking-induced airways diseases. Free Radic Biol Med 1996; 21: 669-681.

2. Rahman I, Morrison D, Donaldson K, MacNee W. Systemic oxidative stress in asthma, COPD, and smokers. Am J Respir Crit Care Med 1996; 154: 1055-1060.

3. Morcillo EJ, Estera J, Cortijo J. Oxidative stress and pulmonary inflammation: pharmacological intervention with antioxidants. Pharmacol Res 1999; 40: 393-404.

4. Brennan FM, Maini RN, Feldmann M. Cytokine expression in chronic inflammatory disease. $\mathrm{Br}$ Med Bull 1995; 51: 368-384.

5. Rahman I, MacNee W. Role of transcription factors in inflammatory lung diseases. Thorax 1998; 53: 601-612.

6. Deneke SM, Fanburg BL. Regulation of cellular glutathione. Am J Physiol 1989; 257: L163-L173.

7. Brown LAS. Glutathione protects signal transduction in type II cells under oxidant stress. Am J Physiol 1994; 266: L172-L177.

8. Droge W, Schulze-Osthoff K, Mihm S, et al. Functions of glutathione and glutathione disulfide in immunology and immunopathology. FASEB $J$ 1994; 8: 1131-1138.

9. Hall AG. The role of glutathione in the regulation of apoptosis. Eur J Clin Invest 1999; 29: 238-245.

10. Richer C, Cogvadze V, Laffranchi R, Schlapbach R, Schweizer M, Suter M. Oxidants in mitochondria: from physiology to diseases. Biochim Biophys Acta 1995; 127: 67-74.

11. Tyagi SC, Kumar S, Border S. Reduction-oxidation (redox) state regulation of extracellular matrix metalloproteinases and tissue inhibitors in cardiac normal and transformed fibroblast cells. J Cell Biochem 1996; 611: $139-151$. 
12. Evans MD, Church DF, Pryor WA. Aqueous cigarette tar extracts damage human $\alpha$-1-proteinase inhibitor. Chem Biol Interact 1991; 79: 151-164.

13. Li XY, Donaldson K, Rahman I, MacNee W. An investigation of the role of glutathione in the increased permeability induced by cigarette smoke in vivo and in vitro. Am Rev Respir Crit Care Med 1994; 149: 15181525.

14. Lannan S, Donaldson K, Brown D, MacNee W. Effects of cigarette smoke and its condensates on alveolar cell injury in vitro. Am J Physiol 1994; 266: L92-L100.

15. van Klaveren RJ, Demedts $M$, Nemery B. Cellular glutathione turnover in vitro, with emphasis on type II pneumocytes. Eur Respir J 1997; 10: 1392-1400.

16. Cantin AM, Hubbard RC, Crystal RG. Glutathione deficiency in the epithelial lining fluid of the lower respiratory tract in idiopathic pulmonary fibrosis. Am Rev Respir Dis 1989; 139: 370-372.

17. MacNee W, Rahman I. Oxidants/antioxidants in idiopathic pulmonary fibrosis. Thorax 1995; 50: S53-S58.

18. Bunnel E, Pacht ER. Oxidised glutathione is increased in the alveolar fluid of patients with the adult respiratory distress syndrome. Am Rev Respir Dis 1993; 148: 11741178 .

19. Roum JH, Behl R, McElvancy NG, Borok Z, Crystal RG. Systemic deficiency of glutathione in cystic fibrosis. $J$ Appl Physiol 1993; 75: 2419-2424.

20. Baz A, Tapson VF, Roggli VL, Tright PV, Piantodqsi CA. Glutathione depletion in epithelial lining fluid of lung allograft patients. Am J Respir Crit Care Med 1996; 153: 742-746.

21. Buhl R, Holroyd KJ, Mastrangeli A, et al. Systemic glutathione deficiency in symptom-free HIV-seropositive individuals. Lancet 1989; ii: 1294-1298.

22. Smith LJ, Houston M, Anderson J. Increased levels of glutathione in bronchoalveolar lavage fluid from patients with asthma. Am Rev Respir Dis 1993; 147: 1461-1464.

23. Cantin AM, North SL, Hubbard RC, Crystal RG. Normal alveolar epithelial lining fluid contains high levels of glutathione. Am J Physiol 1987; 63: 152-157.

24. Morrison D, Rahman I, Lannan S, MacNee W. Epithelial permeability, inflammation and oxidant status in the airspaces of chronic smokers. Am J Respir Crit Care Med 1999; 159: 1-8.

25. Pacht ER, Diaz P, Clanton T, Hart J, Gadek I. Epithelial lining fluid (ELF) glutathione is not decreased in HIV+ smokers with premature emphysema. Am J Respir Crit Care Med 1999; 159: A885.

26. Rahman I, Skwarska E, Henry M, et al. Systemic and pulmonary oxidative stress in idiopathic pulmonary fibrosis. Free Radic Biol Med 1999; 27: 60-68.

27. Galloway DC, Blake DG, Shepherd AG, McLellan LI. Regulation of human $\gamma$-glutamylcysteine synthetase: coordinate induction of the catalytic and regulatory subunits in HepG2 cells. Biochem J 1997; 328: 99-104.

28. Mulcahy RT, Wartman MA, Bailey HH, Gipp JJ. Constitutive and $\beta$-napthoflavone-induced expression of the human $\gamma$-glutamylcysteine synthetase heavy subunit gene is regulated by a distal antioxidant response element/TRE sequence. J Biol Chem 1997; 272: 7445 7454 .

29. Rahman I, Lawson MF, Smith CAD, Harrison DJ, MacNee W. Induction of $\gamma$-glutamylcysteine synthetase by cigarette smoke is associated with AP-1 in human alveolar epithelial cells. FEBS Lett 1996; 396: 21-25.

30. Rahman I, Smith CAD, Antonicelli F, MacNee W. Characterisation of $\gamma$-glutamylcysteine-heavy subunit gene promoter: critical role for AP-1. FEBS Lett 1998; 427: 129-133.

31. Brigham KL. Oxidant stress and adult respiratory distress syndrome. Eur Respir J 1990; 3: 482s-484s.

32. Brown DM, Drost E, Donaldson K, MacNee W. Deformability and CD11/CD18 expression of sequestered neutrophils in normal and inflamed lungs. Am $J$ Respir Cell Mol Biol 1995; 13: 531-539.

33. Rochelle LG, Fischer BM, Adler KB. Concurrent production of reactive oxygen and nitrogen species by airway epithelial cells in vitro. Free Radic Biol Med 1998; 24: 863-868.

34. van Klaveren RJ, Roelant C, Boogaerts M, Demedts M, Nemery B. Involvement of an $\mathrm{NAD}(\mathrm{P}) \mathrm{H}$ oxidase-like enzyme in superoxide anion and hydrogen peroxide generation by rat type II cells. Thorax 1997; 52: 465-471.

35. Knaapen AM, Seiler F, Schilderman PAEL, et al. Neutrophils cause oxidative DNA damage in alveolar epithelial cells. Free Radic Biol Med 1999; 27: 234-240.

36. Lamb NJ, Gutteridge JM, Baker C, Evans TW, Quinlan GJ. Oxidative damage to proteins of bronchoalveolar lavage fluid in patients with acute respiratory distress syndrome: evidence for neutrophil-mediated hyxroxylation, nitration, and chlorination. Crit Care Med 1999; 27: $1738-1744$.

37. Uchida K, Shiraishi M, Naito Y, Torii N, Nakamura Y, Osawa T. Activation of stress signaling pathways by the end product of lipid peroxidation. J Biol Chem 1999; 274 : 2234-2242.

38. Nightingale JA, Rogers DF, Barnes PJ. Effect of inhaled ozone on exhaled nitric oxide, pulmonary function, and induced sputum in normal and asthmatic subjects. Thorax 1999; 54: 1061-1090.

39. O'Byrne PM, Walters EH, Gold BD, et al. Neutrophil depletion inhibits airway hyperresponsiveness induced by ozone exposure in dogs. Am Rev Respir Dis 1984; 130: 214-219.

40. Pryor WA, Prier DG, Church DF. Electron-spin resonance study of mainstream and sidestream cigarette smoke: nature of the free radicals in gasphase smoke and in cigarette tar. Environ Health Perspect 1983; 47: 345-355.

41. Drost EM, Selby C, Lannan S, Lowe GD, MacNee W. Changes in neutrophil deformability following in vitro smoke exposure: mechanism and protection. Am J Respir Cell Mol Biol 1992; 6: 287-295.

42. MacNee W, Wiggs BB, Berzberg AS, Hogg JC. The effect of cigarette smoking on neutrophil kinetics in human lungs. N Engl J Med 1989; 321: 924-928.

43. Wright JL, Sun JP, Churg A. Cigarette smoke exposure causes constriction of rat lung. Eur Respir J 1999; 14: 1095-1099.

44. Langley-Evans SC, Phillips GJ, Jackson AA. Sulphur dioxide: a potent glutathione depleting agent. Comp Biochem Physiol C Pharmacol Toxicol Endocrinol 1996; 114: 89-98.

45. Velsor LW, Postlethwait EM. $\mathrm{NO}_{2}$-induced generation of extracellular reactive oxygen is mediated by epithelial lining layer antioxidants. Am J Physiol 1997; 273: L1265L1275.

46. Jenkins HS, Devalia JL, Mister RL, Bevan AM, Rusznak C, Davies RJ. The effect of exposure to ozone and nitrogen dioxide on the airwway response of atopic asthmatics to inhaled allergen: dose- and time-dependent effects. Am J Respir Crit Care Med 1999; 160: 33-39.

47. van der Vliet A, Eiserich JP, Shigenaga MK, Cross CE. Reactive nitrogen species and tyrosine nitration in the respiratory tract: epiphenomena or a pathobiologic 
mechanism of disease? Am J Respir Crit Care Med 1999; 160: 1-9.

48. Stringer B, Kobzik L. Environmental particulatemediated cytokine production in lung epithelial cells (A549): role of pre-existing inflammation and oxidant stress. J Toxicol Environ Health 1998; 55: 31-44.

49. Janssen-Heininger YMW, Macara I, Mossman BT. Cooperativity between oxidants and tumor necrosis factor in the activation of nuclear factor- $\mathrm{KB} . A m \mathrm{~J}$ Respir Cell Mol Biol 1999; 20: 942-952.

50. Bowie N, Moynagh PN, O'Neill LAJ. Lipid peroxidation is involved in the activation of NF- $\mathrm{KB}$ by tumour necrosis factor but not interleukin-1 in the human endothelial cell line ECV304. J Biol Chem 1997; 272: 25941-25950.

51. Ginn-Pease ME, Whisler RL. Optimal NF-кB mediated transcriptional responses in Jurkat $\mathrm{T}$ cells exposed to oxidative stress are dependent on intracellular glutathione and costimulatory signals. Biochem Biophys Res Commun 1996; 225: 695-702.

52. Jahngen-Hodge J, Obin MS, Gong X, et al. Regulation of ubiquitin-conjugating enzymes by glutathione following oxidative stress. J Biol Chem 1997; 273: 28218-28226.

53. Cho S, Urata Y, Iida T, et al. Glutathione downregulates the phosphorylation of I $\mathrm{KB}$ : autoloop regulation of the NF- $\mathrm{KB}$-mediated expression of NF- $\mathrm{KB}$ subunits by TNF$\alpha$ in mouse vascular endothelial cells. Biochem Biophys Res Commun 1998; 253: 104-108.

54. Ward PA. Role of complement, chemokines and regulatory cytokines in acute lung injury. Ann N Y Acad Sci 1996; 796: 104-112.

55. Akira S, Kishimoto A. NF-IL6 and NF- $\mathrm{BB}$ in cytokine gene regulation. Adv Immunol 1997; 65: 1-46.

56. Abate C, Patel L, Rausher FJ, Curran T. Redox regulation of fos and jun DNA-binding activity in vitro. Science 1990; 249: 1157-1161.

57. Bergelson S, Pinkus R, Daniel V. Intracellular glutathione levels regulate Fos/Jun induction and activation of glutathione S-transferase gene expression. Cancer Res 1994; 54: 36-40.

58. Galter D, Mihm S, Droge W. Distinct effects of glutathione disulphide on the nuclear transcription factors $\kappa \mathrm{B}$ and the activator protein-1. Eur $J$ Biochem 1994; 221: 639-648.

59. Hirota $\mathrm{K}$, Matsui M, Iwata S, Nishiyama A, Mori K, Yodoi J. AP-1 transcriptional activity is regulated by a direct association between thioredoxin and Ref-1. Proc Natl Acad Sci USA 1997; 94: 3633-3638.

60. Meyer M, Schreck R, Bauerle PA. Hydrogen peroxide and antioxidants have opposite effects on activation of $\mathrm{NF}-\kappa \mathrm{B}$ and AP-1 in intact cells: AP-1 as secondary antioxidant-responsive factor. EMBO J 1993; 12: 20052015.

61. Wilhelm D, Bender K, Knebel A, Angel P. The level of intracellular glutathione is a key regulator for the induction of stress-activated signal transduction pathways including Jun N-terminal protein kinases and p38 kinase by alkylating agents. Mol Cell Biol 1997; 17: 4792-4800.

62. Devalia JL, Davies RJ. Airway epithelial cells and mediators of inflammation. Respir Med 1993; 87: 405408.

63. Albelda SM, Smith P.A. Adhesion molecules and inflammatory injury. FASEB $J$ 1994; 8: 504-512.

64. Meister A, Anderson ME. Glutathione. Ann Rev Biochem 1983; 52: 711-760.

65. Huang CS, Chang LS, Anderson ME, Meister A. Catalytic and regulatory properties of the heavy subunit of rat kidney $\gamma$-glutamylcysteine synthetase. J Biol Chem 1993; 268: 19675-19680.

66. Sekhar KR, Meredith MJ, Kerr LD, et al. Expression of glutathione and $\gamma$-glutamylcysteine synthetase mRNA is Jun dependent. Biochem Biophys Res Commun 1997; 234: 588-593.

67. Tomonari A, Nishio K, Kurokawa $\mathrm{H}$, et al. Identification of cis-acting DNA elements of the human $\gamma$-glutamylcysteine synthetase heavy subunit gene. Biochem Biophys Res Commun 1997; 232: 522-527.

68. Tanaka $\mathrm{T}$, Uchiumi $\mathrm{T}$, Kohno $\mathrm{K}$, et al. Glutathione homeostasis in human hepatic cells: overexpression of $\gamma$ glutamylcysteine synthetase gene in cell lines resistant to buthionine sulfoximine, an inhibitor of glutathione synthesis. Biochem Biophys Res Commun 1998; 246: 398403.

69. Cho S, Hazama M, Urata Y, et al. Protective role of glutathione synthesis in response to oxidized low density lipoprotein in human vascular endothelial cells. Free Radic Biol Med 1999; 26: 589-602.

70. Rahman I, Bel A, Mulier B, et al. Transcriptional regulation of $\gamma$-glutamylcysteine synthetase-heavy subunit by oxidants in human alveolar epithelial cells. Biochem Biophys Res Commun 1996; 229: 832-837.

71. Rahman I, Bel A, Mulier B, Donaldson K, MacNee W. Differential effects of oxidants and dexamethasone on $\gamma$ glutamylcysteine synthetase and $\gamma$-glutamyl trans-peptidase in alveolar epithelial cells. Am J Physiol 1998; 275 : L80-L86.

72. Shi MM, Kugelman A, Iwamoto T, Tian L, Forman HJ. Quinone-induced oxidative stress elevates glutathione and induces $\gamma$-glutamylcysteine synthetase activity in rat lung epithelial L2 cells. J Biol Chem 1994; 269: 2651226517.

73. Tian L, Shi MM, Forman HJ. Increased transcription of the regulatory subunit of $\gamma$-glutamylcysteine synthetase in rat lung epithelial L2 cells exposed to oxidative stress or glutathione depletion. Arch Biochem Biophys 1997; 342: 126-133.

74. Liu RM, Hu H, Robison TW, Forman HJ. Increased $\gamma$ glutamylcysteine synthetase and $\gamma$-glutamyltrans-peptidase activities enhance resistance of rat lung epithelial L2 cells to quinone toxicity. Am J Respir Cell Mol Biol 1996; 14: 192-197.

75. Galloway DC, McLellan LI. Inducible expression of the gamma glutamylcysteine synthetase light subunit by $t$ butyl hydroquinone in HepG2 cells is not dependent on an antioxidant-responsive element. Biochem J 1998; 336: 535-539.

76. Liu RM, Gao L, Choi J, Forman HJ. r-glutamylcysteine synthetase: mRNA stabilisation and independent subunit transcription by 4-hydroxy-2-nonenal. Am $J$ Physiol 1998; 275: L861-869.

77. Duan D, Bukpitt AR, Pinkerton KE, Ji C, Ploppoer GG. Ozone-induced alterations in glutathione in lung subcompartments of rats and monkeys. Am J Respir Cell Mol Biol 1996; 14: 70-75.

78. Monova H, Mulcahy RT. An electrophile response element (EpRE) regulates $\beta$-naphthoflavone induction of the human $\gamma$-glutamylcysteine synthetase regulatory subunit gene: constitutive expression is mediated by an adjacent AP-1 site. J Biol Chem 1998; 273: 1468314689.

79. Lapperre TS, Jimenez LA, Antonicelli F, et al. Apocynin increases glutathione synthesis and activates AP-1 in human alveolar epithelial cells. FEBS Lett 1999; 443: 235-239. 
80. Eaton DL, Hamel DM. Increase in $\gamma$-glutamylcysteine synthetase activity as a mechanism for butylated hydroxyanisole-mediated elevation of hepatic glutathione. Toxicol Appl Pharmacol 1994; 126: 145-149.

81. Tu Z, Anders MW. Up-regulation of glutamate-cysteine ligase gene expression by butylated hyoxytoluene is mediated by transcription factor AP-1. Biochem Biophys Res Commun 1998; 244: 801-805.

82. Moellering D, McAndrew J, Jo H, Darley-Usmar VM. Effects of pyrrolidine dithiocarbamate on endothelial cells: protection against oxidative stress. Free Radical Biol Med 1999; 26: 1138-1145.

83. Wild AC, Mulcahy RT. Pyrrolidine dithiocarbamate upregulates the expression of the genes encoding the catalytic and regulatory subunits of $\gamma$-glutamylcysteine synthetase and increases intracellular glutathione levels. Biochem J 1999; 338: 659-665.

84. Liu RM, Vasiliou V, Zhu H, et al. Regulation of (Ah) gene battery enzymes and glutathione levels by 5,10 dihydroindeno(1,2-b) indole in mouse hepatoma cell lines. Carcinogenesis 1994; 15: 2347-2352.

85. Morales A, Garcia-Ruiz C, Miranda M, et al. Tumour necrosis factor increases hepatocellular glutathione by transcriptional regulation of the heavy subunit chain of $\gamma$ glutamylcysteine synthetase. J Biol Chem 1997; 272: 30371-30379.

86. Rahman I, Antonicelli F, MacNee W. Molecular mechanism of the regulation of glutathione synthesis by tumour necrosis factor- $\alpha$ and dexamethasone in human alveolar epithelial cells. J Biol Chem 1999; 274: 50885096.

87. Urata $\mathrm{Y}$, Yamamoto $\mathrm{H}$, Goto $\mathrm{S}$, et al. Long exposure to high glucose concentration impairs the responsive expression of $\gamma$-glutamylcysteine synthetase by interleukin$1 \beta$ and tumor necrosis factor- $\alpha$ in mouse endothelial cells. J Biol Chem 1996; 271: 15146-15152.

88. Moellering D, McAndrew J, Patel RP, et al. The induction of GSH synthesis by nanomolar concentrations of NO in endothelial cells: a role of $\gamma$-glutamylcysteine synthetase and $\gamma$-glutamyltranspeptidase. FEBS Lett 1999; 448: 292 296.

89. White AC, Maloney EK, Boustani MR, Hassoun PM, Fanburg BL. Nitric oxide increases cellular glutathione levels in rat lung fibroblasts. Am Respir Cell Mol Biol 1995; 13: 442-448.

90. Moellering D, McAndrew J, Patel RP, et al. Nitric oxidedependent induction of glutathione synthesis through increased expression of $\gamma$-glutamylcysteine synthetase. Arch Biochem Biophys 1998; 358: 74-82.

91. Iwanga $\mathrm{M}$, Mori $\mathrm{K}$, Iida $\mathrm{T}$, et al. Nuclear factor $\kappa \mathrm{B}$ dependent induction of $\gamma$-glutamylcysteine synthetase by ionizing radiation in T98G human glioblastoma cells. Free Radic Biol Med 1998; 24: 1256-1268.

92. Morales A, Miranda M, Sanchez-Reyes A, Colell A, Biete A, Fernandez-Checa JC. Transcriptional regulation of the heavy subunit chain of $\gamma$-glutamylcysteine synthetase by ionizing radiation. FEBS Lett 1998; 427 : $15-20$.

93. Chung AS, Maines MD. Effect of selenium on glutathione metabolism: induction of $\gamma$-glutamylcysteine synthetase and glutathione reductase in the rat liver. Biochem Pharmacol 1981; 30: 3217-3223.

94. Ogino T, Kawabata T, Awai M. Stimulation of glutathione synthesis in iron loaded mice. Biochim Biophys Acta 1989; 1006: 131-135.

95. Hatcher EL, Chen Y, Kang A. Cadmium resistance in A549 cells correlates with elevated glutathione content but not antioxidant enzymatic activities. Free Radic Biol Med 1995; 19: 805-812.

96. Woods JS, Ellis ME. Up-regulation of glutathione synthesis in rat kidney by methyl mercury: relationship to mercury-induced oxidative stress. Biochem Pharmacol 1995; 50: 1719-1724.

97. Yao KS, Godwin AK, Johnson SW, Ozols RF, O'Dwyer PJ, Hamilton TC. Evidence for altered regulation of $\gamma-$ glutamylcysteine synthetase gene expression among cisplatin-sensitive and cisplatin-resistant human ovarian cancer cell lines. Cancer Res 1995; 55: 4367-4374.

98. Mulcahy RT, Bailey H, Gipp JJ. Up-regulation of $\gamma$ glutamylcysteine synthetase activity in melphalan-resistant human multiple myeloma cells expressing increased glutathione levels. Cancer Chemother Pharmacol 1994; 34: 67-71.

99. Pan Z, Perez-Polo R. Regulation of $\gamma$-glutamylcysteine synthetase activity by nerve growth factor. Int $J \mathrm{Dev}$ Neurosci 1996; 14: 559-566.

100. Choi J, Opalenik SR, Wu W, Thompson JA, Forman HJ. Modulation of glutathione synthetic enzymes by acid fibroblast growth factor. Arch Biochem Biophys 2000; 375: 201-209.

101. Kondo T, Yoshida K, Urata T, Goto S, Gasa S, Taniguchi N. $\gamma$-Glutamylcysteine synthetase and sctive transport of glutathione S-conjugate are responsive to heat shock in K562 erythroid cells. J Biol Chem 1993; 268: 2036620372.

102. Pinkus R, Weiner LM, Daniel V. Rote of oxidants and antioxidants in the induction of AP-1, NF- $\mathrm{KB}$ and glutathione S-transferase gene expression. $J$ Biol Chem 1996; 271: 13422-13429.

103. Cai J, Huang Z, Lu SC. Differential regulation of $\gamma$ glutamylcysteine synthetase heavy and light subunit gene expression. Biochem J 1997; 326: 167-172.

104. Kondo T, Higashiyama Y, Goto S, et al. Regulation of $\gamma$ glutamylcysteine synthetase expression in response to oxidative stress. Free Radic Res 1999; 31: 325-334.

105. Bella DL, Hirschberger LL, Hosokawa Y, Stipanuk MH. Mechanisms involved in the regulation of key enzymes of cysteine metabolism in rat liver in vivo. Am J Physiol 1999; 276: E326-E335.

106. Gomi A, Masuzawa T, Ishikawa T, Kuo MT. Posttranscriptional regulation of MRP/GS-X pump and $\gamma$-glutamylcysteine synthetase expression by 1 (4-amino 2-methyl-5-pyrimidinyl)-methyl-3-(2-chloroeth-yl)-3-nitrosourea and by cycloheximide in human glioma cells. Biochem Biophys Res Commun 1997; 239: 51-56.

107. Lu SC, Kuhlenkamp J, Garcia-Ruiz C, Kaplowitz N. Hormone-mediated down-regulation of hepatic glutathione synthesis in the rat. $J$ Clin Invest 1991; 88: 260 269.

108. Sun WM, Huang ZZ, Lu SC. Regulation of $\gamma-$ glutamylcysteine synthetase by protein phosphorylation. Biochem J 1996; 320: 321-328.

109. White AC, Das SK, Fanburg BL. Reduction of glutathione is associated with growth restriction and enlargement of bovine pulmonary artery endothelial cells produced by transforming growth factor- $\beta 1$. Am J Respir Cell Mol Biol 1992; 6: 364-368.

110. Arsalane K, Dubois CM, Muanz T, et al. Transforming growth factor-1 is a potent inhibitor of glutathione synthesis in the lung epithelial cell line A549: transcriptional effect on the GSH rate-limiting enzyme $\gamma$-glutamylcysteine synthetase. Am J Respir Cell Mol Biol 1997; 17: 599-607.

111. Rishikof DC, Krupsky M, Goldstein RH. The effect of 
prostaglandin E2 on cystine uptake and glutathione synthesis by human lung fibroblasts. Biochim Biophys Acta 1998; 1405: 155-160.

112. Griffith OW, Bridges RJ, Meister A. Transport of $\gamma-$ glutamyl amino acids: role of glutathione and $\gamma$-glutamyl transpeptidase. Proc Natl Acad Sci USA 1979; 76: 63196322 .

113. Rouzer CA, Scott WA, Griffith OW, Hammill AL, Cohn ZA. Glutathione metabolism in resting and phagocytizing peritoneal macrophages. J Biol Chem 1982; 257: 2002-2008.

114. Abbott WA, Bridges RJ, Meister A. Extracellular metabolism of glutathione accounts for its disappearance from the basolateral circulation of the kidney. J Biol Chem 1984; 259: 15393-15400.

115. Griffith OW, Meister A. Translocation of intracellular glutathione to membrane-bound $\gamma$-glutamyl transpeptidase as a discrete step in the $\gamma$-glutamyl cycle: glutathionuria after inhibition of transpeptidase. Proc Natl Acad Sci USA 1979; 76: 268-272.

116. Berggren M, Dawson J, Moldeus P. Glutathione biosynthesis in the isolated perfused rat lung: utilization of extracellular glutathione. FEBS Lett 1981; 176: 189192.

117. Van Klaveren RJ, Demedts M, Nemery B. Cellular glutathione turnover in vitro, with emphasis on type II pneumocytes. Eur Respir J 1997; 10: 1392-1400.

118. Kugelman A, Choy HA, Liu R, Shi MM, Gozal E, Forman HJ. $\gamma$-Glutamyl transpeptidase is increased by oxidative stress in rat alveolar L2 epithelial cells. $\mathrm{Am} \mathrm{J}$ Respir Cell Mol Biol 1994; 11: 586-592.

119. Deneke SM, Susanto I, Vogel KA, Williams CE, Lawrence RA. Mechanism of use of extracellular glutathione by lung epithelial cells and pulmonary artery endothelial cells. Am J Respir Cell Mol Biol 1995; 12: 662-668

120. Bannai S, Tateishi N. Role of membrane transport in metabolism and function of glutathione in mammals. $J$. Membr Biol 1986; 89: 1-8.

121. Deneke SM, Gershoff SN, Fanburg BL. Potentiation of oxygen toxicity in rats by dietary protein or amino acid deficiency. J Appl Physiol 1983; 54: 147-151.

122. Deneke SM, Lynch BA, Fanburg BL. Transient depletion of lung glutathione by diethylmaleate enhances oxygen toxicity. J Appl Physiol 1985; 58: 571-574.

123. Bannai S. Transport of cystine and cysteine in mammalian cells. Biochim Biophys Acta 1984; 779: 289-306.

124. Bai C, Brown LAS, Jones DP. Glutathione transport by type II cells in perfused rat lung. Am J Physiol 1994; 267 : L447-L455.

125. Bukowski DM, Deneke SM, Lawrence RA, Jenkinson SG. A noninducible cystine transport system in rat alveolar type II cells. Am J Physiol 1995; 268: L21-L26.

126. Hagen TM, Wierzbicka GT, Sillau AH, Bowman BB, Jones DP. Bioavailability of dietary glutathione: effect of plasma concentration. Am J Physiol 1990; 259: G524G529.

127. Li H, Marshall ZM, Whorton AR. Stimulation of cystine uptake by nitric oxide: regulation of endothelial cell glutathione levels. Am J Physiol 1999; 276: C803-C811.

128. Liu RM, Hu H, Robison TW, Forman HJ. Increased $\gamma-$ glutamylcysteine synthetase and $\gamma$-glutamyltrans-peptidase activities enhance resistance of rat lung epithelial L2 cells to quinone toxicity. Am J Respir Cell Mol Biol 1996; 114: 192-197.

129. Bannai S, Sato H, Ishii T, Taketani S. Enhancement of glutathione levels in mouse peritoneal macrophages by sodium arsenite, cadmium chloride and glucose/glucose oxidase. Biochem Biophys Acta 1991; 1092: 175-179.

130. Deneke SM. Induction of cystine transport in bovine pulmonary artery endothelial cells by sodium arsenite. Biochim Biophys Acta 1992; 1109: 127-131.

131. Deneke SM, Lynch BA, Fanburg BL. Effects of low protein diets or feed restriction on rat lung glutathione and oxygen toxicity. $J$ Nutr $1985 ; 115$ : 726-732.

132. Phelps DT, Deneke SM, Daley D, Fanburg BL. Elevation of glutathione levels in bovine pulmonary endothelial cells by $\mathrm{N}$-acetylcysteine. Am J Respir Cell Mol Biol 1992; 7: 293-298.

133. Susanto I, Wright SE, Lawson RS, Williams CE, Deneke SM. Metallothionein, glutathione, and cystine transport in pulmonary artery endothelial cells and NIH/3T3 cells. Am J Physiol 1998; 274: L296-L300.

134. Deneke SM, Steiger V, Fanburg B. Effect of hyperoxia on glutathione levels and glutamic acid uptake in endothelial cells. J Appl Physiol 1987; 63: 1966-1971.

135. Phelps DT, Deneke SM, Baxter DF, Fanburg BL. Erythrocytes fail to induce glutathione levels in response to diethyl maleate or hyperoxia. Am J Physiol 1989; 257: L272-L276.

136. Lu SC, Ge JL, Huang HY, Kuhlenkamp J, Kaplowitz N. Thiol-disulfide effects on hepatic glutathione transport. Studies in cultured rat hepatocytes and perfused livers. $J$ Clin Invest 1993; 92: 1188-1197.

137. van Klaveren RJ, Hoet PH, Demedts M, Nemery B. Investigation of the transport of intact glutathione in human and rat type II pneumocytes. Free Radic Res 1999; 30: 371-381.

138. Iantomasi T, Favilli F, Marraccini P, Magaldi T, Bruni P, Vincenzini MT. Glutathione transport system in human small intestine epithelial cells. Biochim Biophys Acta 1997; 1330: 274-283.

139. Lu SC, Ge JL, Kuhlenkamp J, Kaplowitz N. Insulin and glucocorticoid dependence of hepatic $\gamma$-glutamylcysteine synthetase and GSH synthesis in the rat: studies in cultured hepatocytes and in vivo. J Clin Invest 1992; 90: 524-532.

140. Lu SC, Kulenkamp J, Garica-Ruiz C, Kaplowitz N. Hormone-mediated downregulation of hepatic glutathione synthesis in the rat. J Clin Invest 1991; 88: 260269.

141. Wong GH, Goeddel DV. Induction of manganous superoxide dismutase by tumor necrosis factor: possible protective mechanism. Science 1988; 242: 941-944.

142. Keating SVM, Collins PD, Scott DM, Barnes PJ. Differences in interleukin- 8 and tumour necrosis factorinduced sputum from patients with chronic obstructive pulmonary disease or asthma. Am J Respir Crit Care Med 1996; 153: 530-534.

143. Phelps DT, Ferro TJ, Higgins PJ, Shankar R, Parker DM, Johnson A. TNF- $\alpha$ induces peroxynitrite-mediated depletion of lung endothelial glutathione via protein kinase C. Am J Physiol 1995; 29: L551-L559.

144. Lands LC, Grey V, Smountas AA, Kramer VG, McKenna D. Lymphocyte glutathione levels in children with cystic fibrosis. Chest 1999; 116: 201-205.

145. Barnes PJ. Mechanism of action of glucocorticoids in asthma. Am J Respir Crit Care Med 1996; 154: S21-S27.

146. Pietarinen-Runtti P, Raivio KO, Saksela M, Asikainen TM, Kinnula VL. Antioxidant enzyme regulation and resistance to oxidants of human bronchial epithelial cells cultured under hypoxic conditions. Am J Respir Cell Mol Biol 1998; 19: 286-292. 
147. Kuo MT, Bao J, Furuichi M, et al. Frequent co-expression of MRP/GS-X pump and $\gamma$-glutamylcysteine synthetase mRNA in drug-resistance cells, untreated tumor cells, and normal mouse tissues. Biochem Pharmacol 1998; 55: 605-615.

148. Oguri $\mathrm{T}$, Fujiwara $\mathrm{Y}$, Isobe $\mathrm{T}$, Katoh $\mathrm{O}$, Watanabe $\mathrm{H}$, Yamakido M. Expression of $\gamma$-glutamylcysteine synthetase and multidrug resistance associated protein (MRP), but not human canalicular multispecific organic anion transporter (cMOAT), genes correlates with exposure of human lung cancers to platinum drugs. Br J Cancer 1998; 77: 1089-1996.

149. Giaccone G, van Ark-Otte J, Rubio GJ, et al. MRP is frequently expressed in human lung-cancer cell lines, in non-small-cell lung cancer and in norrnal lungs. Int $J$ Cancer 1996; 66: 760-767.

150. Wright SR, Boag AH, Valdimarsson $\mathrm{G}$, et al. Immunohistochemical detection of multidrug resistance protein in human lung cancer and normal lung. Clin Cancer Res 1998; 4: 2279-2289.

151. Wijnholds J, Evers R, van Leusden MR, et al. Increased sensitivity to anticancer drugs and decreased inflammatory response in mice lacking the multidrug resistanceassociated protein. Nat Med 1997; 3: 1275-1279.

152. Mulier B, Rahman I, Watchorn T, Donaldson K, MacNee W, Jeffery PK. Hydrogen peroxide-induced epithelial injury: the protective role of intracellular non protein thiols (NPSH). Eur Respir J 1998; 11: 384-391.

153. Border WA, Noble N. Transforming growth factor- $\beta$ in tissue fibrosis. N Engl Med 1994; 331: 1286-1292.

154. De Boer WI, van Schadewijk A, Sont JK, et al. Transforming growth factor $\beta 1$ and recruitment of macrophages and mast cells in airways in chronic obstructive pulmonary disease. Am J Respir Crit Care Med 1998; 158: 1-7.

155. Redington AE, Madden J, Frew AJ, et al. Transforming growth factor- $\beta 1$ in asthma: measurement in bronchoalveolar lavage fluid. Am J Respir Crit Care Med 1997; 156: 642-647.

156. Factor VM, Kiss A, Woitach JT, Wirth PJ, Thorgeirsson SS. Disruption of redox homoestasis in the transforming growth factor- $\alpha / c-m y c$ transgenic mouse model of accelerated hepatocarcinogenesis. J Biol Chem 1998; 273: 15846-15853.

157. Uria JA, Jimenez MG, Balbin M, Freije JMP, Lopez-Otin C. Differential effects of transforming growth factor- $\beta$ on the expression of collagenase- 1 and collagenase- 3 in human fibroblasts. J Biol Chem 1998; 273: 9769-9777.

158. Cantin AM, Larivee P, Begin R. Extracellular glutathione suppresses human lung fibroblast proliferation. $\mathrm{Am} \mathrm{J}$ Respir Cell Mol Biol 1990; 3: 79-85.

159. Cai J, Sun WM, Lu SC. Hormonal and cell density regulation of hepatic $\gamma$-glutamylcysteine synthetase gene regulation. Mol Pharmacol 1995; 48: 212-218.

160. Lu SC, Ge JL. Loss of suppression of GSH synthesis at low cell density in primary cultures of rat hepatocytes. $\mathrm{Am}$ J Physiol 1992; 273: C1181-C1189.

161. Frischer H, Kennedy EJ, Chigurupati R, Sivarajan M. Glutathione, cell proliferation, and 1,3-bis-(2-chloroethyl)-1-nitrosourea in K562 leukemia. J Clin Invest 1993; 92: 2761-2767.

162. Messina JP, Lawrence DA. Cell cycle progression of glutathione-depleted human peripheral blood mononuclear cells is inhibited at S phase. J Immunol 1989; 143: 1974-1981.

163. Shaw JP, Chou IN. Elevation of intracellular glutathione content associated with mitogenic stimulation of quiescent fibroblasts. J Cell Physiol 1986; 129: 193-198.

164. Principe P, Wilson GD, Riley PA, Slater TF. Flow cytometric analysis of protein thiol groups in relation to the cell cycle and the intracellular content of glutathione in rat hepatocytes. Cytometry 1989; 10: 750-761.

165. Li N, Oberley TD. Modulation of antioxidant enzymes, reactive oxygen species, and glutathione levels in manganese superoxide dismutaseoverexpressing NIH/3T3 fibroblasts during the cell cycle. J Cell Physiol 1998; 177: $148-160$.

166. Koyama H, Geddes DM. Genes, oxidative stress, and the risk of chronic obstructive pulmonary disease. Thorax 1998; 53 (Suppl. 2): S10-S14.

167. Barnes PJ. Genetics and pulmonary medicine. 9. Molecular genetics of chronic obstructive pulmonary disease. Thorax 1999; 54: 245-252.

168. Cantlay AM, Smith CAD, Wwallace WA, Yap PL, Lamb D, Harrison DJ. Heterogenous expression and polymorphic genotype of glutathione $S$-transferases in human lung. Thorax 1994; 49: 1010-1014.

169. Smith CAD, Harrison DJ. Association between polymorphism in gene for microsomal epoxide hydrolase and susceptibility to emphysema. Lancet 1997; 350: 630-633.

170. Ishii $\mathrm{T}$, Matsuse $\mathrm{T}$, Teramoto $\mathrm{S}$, et al. Glutathione $\mathrm{S}-$ transferase P1 (GSTP1) polymorphism in patients with chronic obstructive pulmonary disease. Thorax 1999; 54 : 693-696.

171. Yim JJ, Park GY, Lee CT, et al. Genetic susceptibility to chronic obstructive pulmonary disease in Koreans: combined analysis of polymorphic genotypes for microsomal epoxide hydrolase and glutathione S-transferase M1 and T1. Thorax 2000; 55: 121-125.

172. Yoshikawa M, Hiyama K, Ishioka S, Maeda H, Maeda A, Yamakido M. Microsomal epoxide hydrolase genotypes and chronic obstructive pulmonary disease in Japanese. Int J Mol Med 2000; 5: 49-53.

173. Kimura J, Hayakari M, Kumano T, Nakano H, Satoh K, Tsuchida S. Altered glutathione transferase levels in rat skin inflamed due to contact hypersensitivity: induction of the $\alpha$-class subunit 1. Biochem J 1998; 335: 605-610.

174. Massad-Massade L, Chouaib S, Gouyette A. Phenobarbital prevents the inhibitory effects of tumor necrosis factor on glutathione- $S$-transferase $\mu$ in primary culture rat hepatocytes. Anticancer Res 1998; 18: 1833-11838.

175. Walsh AC, Li W, Rosen DR, Lawrence DA. Genetic mapping of GLCLC, the human gene encoding the catalytic subunit of $\gamma$-glutamylcysteine synthetase, to chromosome band $6 \mathrm{pl} 12$ and characterisation of a polymorphic trinucleotide repeat within its $5^{\prime}$-untranslated region. Cytogenet Cell Genet 1996; 75: 114-116.

176. Beutler E, Gelbart T, Kondo T, Matsunaga AT. The molecular basis of a case of $\gamma$-glutamylcysteine synthetase deficiency. Blood 1999; 94: 2890-2894.

177. Sierra-Rivera E, Dasouki M, Summar ML, et al. Assignment of the human gene (GLCLR) that enclodes the regulatory subunit of $\gamma$-glutamylcysteine synthetase to chromosome 1p21. Cytogenet Cell Genet 1996; 72: 252 254.

178. Sierra-Rivera E, Summar ML, Dasouki M, Krishnamani MR, Phillips JA, Freeman ML. Assignment of the gene (GLCLC) that encodes the heavy subunit of $\gamma$-glutamylcysteine synthetase to human chromosome 6. Cytogenet Cell Genet 1995; 70: 278-279.

179. Tsuchiya K, Mulcahy RT, Reid LL, Disteche CM, Kavanagh TJ. Mapping of the glutamate-cysteine ligase catalytic subunit gene (GLCLC) to human chromosome 
$6 \mathrm{pl} 2$ and mouse chromosome 9D-E and of the regulatory subunit gene (GLCLR) to human chromosome 1p21-p22 and mouse chromosome 3H1-3. Genomics 1995; 30: 630-632.

180. Rozet JM, Gerber S, Perrault I, et al. Structure and refinement of the physical mapping of the $\gamma$-glutamylcysteine ligase regulatory subunit (GLCLR) gene to chromosome 1 p22.1 within the critically deleted region of human malignant mesothelioma. Cytogenet Cell Genet 1998; 82: 91-94.

181. Lakshminarayanan V, Drab-Weiss EA, Roebuck KA. Hydrogen peroxide and tumor necrosis factor- $\alpha$ induce differential binding of the redox-responsive transcription factors AP- 1 and NF- $\kappa$ B to the interleukin- 8 promoter in endothelial and epithelial cells. $J$ Biol Chem 1996; 273 : 32670-32678.

182. Watchorn T, Mulier B, MacNee W. Does increasing intracellular glutathione inhibit cytokine-induced nitric oxide release and NF- $\mathrm{\kappa B}$ activation. Am J Respir Crit Care Med 1998; 157: A889.

183. Parmentier M, Drost E, Hirani N, et al. Thiol antioxidants inhibit neutrophil chemotaxis by decreasing release of IL8 from macrophages and pulmonary epithelial cells. Am J Respir Crit Care Med 1999; 159: A27.

184. Berendji D, Kolb-Bachofen V, Meyer KL, Kroncke KD. Influence of nitric oxide on the intracellular reduced glutathione pool: different cellular capacities and strategies to encounter nitric oxide-mediated stress. Free Radic Biol Med 1999; 27: 773-780.

185. Szabo C, Dawson VL. Role of poly(ADP-ribose) synthetase in inflammation and ischaemia-reperfusion. Trends Pharmacol Sci 1998; 19: 287-298.

186. Vodovotz Y, Chesler L, Chong H, et al. Regulation of transforming growth factor $\beta 1$ by nitric oxide. Cancer Res 1999; 59: 2142-2149.

187. Peristeris P, Clark BD, Gatti S, et al. $N$-acetylcysteine and glutathione as inhibitors of tumor necrosis factor production. Cell Immunol 1992; 140: 390-399.

188. Li XY, Rahman I, Donaldson K, MacNee W. Mechanisms of cigarette smoke induced increased airspace permeability. Thorax 1996; 51: 465-471.

189. Rahman I, Li XY, Donaldson K, Harrison DJ, MacNee W. Glutathione homeostasis in alveolar epithelial cells in vitro and lung in vivo under oxidative stress. Am J Physiol 1995; 269: L285-292.

190. Rahman I, Schadewijk AMV, Hiemstra PS, et al. Localisation of $\gamma$-glutamylcysteine synthetase messenger RNA expression in lungs of smokers and patients with chronic obstructive pulmonary disease. Free Radic Biol Med 2000; 28: 920-925.

191. Gilks CB, Price K, Wright JL, Churg A. Antioxidant gene expression in rat lung after exposure to cigarette smoke. Am J Pathol 1998; 152: 269-278.

192. Oguro TM, Hayashi S, Numazawa K, Asakawa A, Yoshida T. Heme oxygenase-1 gene expression by a glutathione depletor, phorone, mediated through AP-1 activation in rats. Biochem Biophys Res Commun 1996; 221: 259-265.

193. Rahman I, Clerch LC, Massaro D. Rat lung antioxidant enzyme induction by ozone. Am J Physiol 1991; 260: L412-L418.

194. Cross CE, van der Vliet A, O'Neill CA, Louie S, Halliwell B. Oxidants, antioxidants, and respiratory trace lining fluids. Environ Health Perspect 1994; 102: 185-191.

195. Hagen TM, Brown LA, Jones DP. Protection against paraquat-induced injury by exogenous GSH in pulmonary alveolar type II cells. Biochem Pharmacol 1986; 35 : 4537-4542.

196. Avissar N, Finkelstein JN, Horowitz S, et al. Extracellular glutathione peroxidase in human lung epithelial lining fluid and in lung cells. Am J Physiol 1996; 270: L173L182.

197. Nishikawa M, Nobumasa K, Ito T, et al. Superoxide mediates cigarette smoke-induced infiltration of neutrophils into the airways through nuclear factor- $\mathrm{\kappa B}$ activation and IL-8 mRNA expression in guinea pigs in vivo. Am J Respir Cell Mol Biol 1999; 20: 189-198.

198. Li XY, Gilmour PS, Donaldson K, MacNee W. Free radical activity and proinflammatory effects of particulate air pollution (PM10) in vivo and in vitro. Thorax 1996; 51: $1216-1222$.

199. Omara FO, Fournier M, Vincent R, Blakley BR. Suppression of rat and mouse lymphocyte function by urban air particulates (Ottawa dust) is reversed by $N$ acetylcysteine. J Toxicol Environ Health 2000; 59: 67-85.

200. Leung KH, Post GB, Menzel DB. Glutathione Ssulfonate, a sulfur dioxide metabolite, as a competitive inhibitor of glutathione $S$-transferase, and its reduction by glutathione reductase. Toxicol Appl Pharmacol 1985; 77: 388-394.

201. Rasmussen TR, Kjaergaard SK, Tarp U, Pedersen OF. Delayed effects of $\mathrm{NO}_{2}$ exposure on alveolar permeability and glutathione peroxidase in healthy humans. Am Rev Respir Dis 1992; 146: 654-659.

202. Keller DA, Menzel DB. Effects of sulfite on glutathione $S$-sulfonate and the glutathione status on lung cells. Chem Biol Interact 1989; 70: 145-156.

203. Gumuslu S, Akbas H, Aliciguzel Y, Agar A, Kucukatay V, Yargicoglu P. Effects of sulfur dioxide inhalation on antioxidant enzyme activities in rat erythrocytes. Ind Health 1998; 36: 70-73.

204. Linden M, Hakansson L, Ohlsson K, et al. Glutathione in bronchoalveolar lavage fluid from smokers is related to humoral markers of inflammatory cell activity. Inflammation 1989; 13: 651-658.

205. Linden M, Rasmussen JB, Pitulainen E, et al. Airway inflammation in smokers with nonobstructive and obstructive chronic bronchitis. Am Rev Respir Dis 1993; 148: 1226-1232.

206. Kokura S, Wolf RE, Yoshikawa T, Granger DN, Aw TY. Molecular mechanisms of neutrophil-endothelial cell adhesion induced by redox imbalance. Circ Res 1999; 84: 516-524.

207. Marui N, Offermann MK, Swerlick R, et al. Vascular cell adhesion molecule-1 (VCAM-1) gene transcription and expression are regulated through an antioxidant sensitive mechanism in human vascular endothelial cells. $J$ Clin Invest 1993; 92: 1866-1874.

208. Aoki T, Suzuki Y, Suzuki K, et al. Modulation of ICAM-1 expression by extra-cellular glutathione in hyperoxiaexposed human pulmonary artery endothelial cells. $\mathrm{Am} \mathrm{J}$ Respir Cell Mol Biol 1996; 15: 319-327.

209. Goldkorn T, Balaban N, Matsukuma K, et al. EGFreceptor phosphorylation and signaling are targeted by hydrogen peroxide redox stress. Am J Respir Cell Mol Biol 1998; 19: 786-798.

210. Nakajima Y, Aoshiba K, Yasui S, Nagai A. Hydrogen peroxide induces apoptosis in bovine tracheal epithelial cells in vitro. Life Sci 1999; 64: 2489-2496.

211. Aoshiba K, Yasui S, Nishimura K, Nagai A. Thiol depletion induces apoptosis in cultured lung fibroblasts. Am J Respir Cell Mol Biol 1999; 21: 54-64.

212. Volm M, Koomagi R, Mattern J. Angiogenesis and 
cigarette smoking in squamous cell lung carcinomas: an immunohistochemical study of 28 cases. Anticancer Res 1999; 19: 333-336.

213. Klekamp JG, Jarzecka K, Perkett EA. Exposure to hyperoxia decreases the expression of vascular endothelial growth factor and its receptors in adult rat lungs. Am J Pathol 1999; 154: 823-831.

214. Liu B, Andrieu-Abadie N, Levade T, Zhang P, Obeid LM, Hannum YA. Glutathione regulation of neutral sphingomyelinase in tumour necrosis factor- $\alpha$-induced cell death. J Biol Chem 1998; 273: 11313-11320.

215. Liu H, Lightfoot R, Stevens JL. Activation of heat shock factor by alkylating agents is triggered by glutathione depletion and oxidation of protein thiols. $J$ Biol Chem 1996; 271: 4805-4812.

216. Lautier D, Luscher P, Tyrrell RM. Endogenous glutathione levels modulate both constitutive and UVA radiation/hydrogen peroxide inducible expression of the human heme oxygenase gene. Carcinogenesis 1992; 13: 227-232.

217. Abe T, Gotoh S, Highashi K. Attenuation by glutathione of hsp72 gene expression induced by cadmium in cisplatin-resistant human ovarian cancer cells. Biochem Pharmacol 1999; 58: 69-76.

218. Meister A. Mitochondrial changes associated with glutathione deficiency. Biochem Biophys Acta 1995; 1271: 35-42.

219. Fahn H, Wang L, Kao S, Chang S, Huang M, Wei Y. Smoking-associated mitochondrial DNA mutation and lipid peroxidation in human lung tissue. Am J Respir Cell Mol Biol 1998; 19: 901-909.

220. Chen K-H, Reece LM, Leary JF. Mitochondrial glutathione modulates TNF- $\alpha$-induced endothelial cell dysfunction. Free Radic Biol Med 1999; 27: 100-109.

221. Esteve MJ, Mompo J, Asuncion JG, et al. Oxidative damage to mitochondrial DNA and glutathione oxidation in apoptosis: studies in vivo and in vitro. FASEB J 1999; 13: $1055-1064$

222. Dumont A, Hehner SP, Hofmann TG, Ueffing M, Droge W, Schmitz ML. Hydrogen peroxide-induced apoptosis is CD95-independent, requires the release of mitochondriaderived reactive oxygen species and the activation of NFkappa B. Oncogene 1999; 18: 747-757.

223. Fernandez-Checa JC, Garcia-Ruiz C, Colell A, et al. Oxidative stress: role of mitochondria and protection by glutathione. Biofactors 1998; 8: 7-11.

224. O'Donovan DJ, Katkin JP, Tamura T, et al. Gene transfer of mitochondrially targeted glutathione reductase protects H441 cells from $t$-butyl hydroperoxide-induced oxidant stress. Am J Respir Cell Mol Biol 1999; 20: 256-263.

225. Arai $\mathrm{M}$, Imai $\mathrm{H}$, Koumura $\mathrm{T}$, et al. Mitochondrial phospholipid hydroperoxide glutathione peroxidase plays a major role in preventing oxidative injury to cells. $J$ Biol Chem 1999; 274: 4924-4933.

226. Tyagi SC. Homocysteine redox receptor and regulation of extracellular matrix components in vascular cells. $\mathrm{Am} J$ Physiol 1998; 274: C396-C405.

227. Lois M, Brown LA, Moss IM, Roman J, Guidot DM. Ethanol ingestion increases activation of matrix metalloproteinases in rat lungs during acute endotoxemia. $A m J$ Respir Crit Care Med 1999; 160: 1354-1360.

228. Foda HD, Rollo EE, Brown P, et al. Attenuation of oxidant-induced lung injury by the synthetic matrix metalloproteinase inhibitor BB-3103. Ann N Y Acad Sci 1999; 878: 650-653.

229. Choi AM, Elbon CL, Bruce SA, Bassett DJ. Messenger
RNA levels of lung extracellular matrix proteins during ozone exposure. Lung 1994; 172: 15-30.

230. Hagen K, Zhu C, Melefors O, Hultcrantz R. Susceptibility of cultured rat hepatocytes to oxidative stress by peroxides and iron. The extracellular matrix affects the toxicity of ter-butyl hydroperoxide. Int J Biochem Cell Biol 1999; 31: 499-508.

231. Peterson JD, Herzenberg LA, Vasquez K, Waltenbaugh C. Glutathione levels in antigen-presenting cells modulate Th1 versus Th2 response patterns. Proc Natl Acad Sci USA 1998; 95: 3071-3076.

232. Herzenberg LA, De Rosa SC, Dubs JG, et al. Glutathione deficiency is associated with impaired survival in HIV disease. Proc Natl Acad Sci USA 1997; 94: 1967-1972.

233. Walmsley SL, Winn LM, Harrison ML, Uetrecht JP, Wells PG. Oxidative stress and thiol depletion in plasma and peripheral blood lymphocytes from HIV-infected patients: toxicological and pathological implications. AIDS 1997; 11: 1689-1697.

234. Jeannin P, Delneste Y, Lecoanet-Henchoz S, et al. Thiols decrease human interleukin-4 production and IL-4induced immunoglobulin synthesis. J Exp Med 1995; 182: $1785-1792$.

235. Iwata $\mathrm{S}$, Hori $\mathrm{T}$, Sato $\mathrm{N}$, et al. Adult $\mathrm{T}$ cell leukemia (ATL)-derived factor/human thioredoxin prevents apoptosis of lymphoid cells induced by L-cystine and glutathione depletion: possible involvement of thiol-mediated redox regulation in apoptosis caused by pro-oxidant state. J Immunol 1997; 158: 3108-3117.

236. Fidelus RK, Tsan MF. Glutathione and lymphocyte activation: a function of ageing and auto-immune disease. Immunology 1987; 61: 503-508.

237. Olsson B, Johansson M, Gabrielson J, Bolme P. Pharmacokinetics of reduced and oxidised N-acetylcysteine. Eur J Clin Pharmacol 1988; 34: 77-82.

238. Boman G, Backer U, Larsson S, Melander B, Wahlander L. Oral acetylcysteine reduces exacerbation rate in chronic bronchitis. Eur J Respir Dis 1983; 64: 405-415.

239. Bridgeman MME, Marsden M, MacNee W, Flenley DC, Ryle AP. Cysteine and glutathione concentrations in plasma and bronchoalveolar lavage fluid after treatment with $N$-acetylcysteine. Thorax 1991; 46: 39-42.

240. Bridgeman MME, Marsden M, Selby C, Morrison D, MacNee W. Effect of $\mathrm{N}$-acetyl cysteine on the concentrations of thiols in plasma, bronchoalveolar lavage fluid and lining tissue. Thorax 1994; 49: 670-675.

241. Meyer A, Buhl R, Magnussen $\mathrm{H}$. The effect of oral $\mathrm{N}$ acetylcysteine on lung glutathione levels in idiopathic pulmonary fibrosis. Eur Respir $J$ 1994; 7: 431-436.

242. Eklund A, Eriksson O, Hakansson L, et al. Oral $\mathrm{N}$ acetylcysteine reduces selected humoral markers of inflammatory cell activity in BAL fluid from healthy smokers: correlation to effects on cellular variables. Eur Respir J 1988; 1: 832-838.

243. Behr J, Maier K, Degenkolb B, Kromback C, Vogelmeier C. Antioxidative and clinical effects of high-dose $\mathrm{N}$ acetylcysteine in fibrosing alveolitis: adjunctive therapy to maintenance immunosuppression. Am J Respir Crit Care Med 1997; 156: 1897-1901.

244. Suter PM, Domenighetti G, Schaller MD, Lavarriere MC, Ritz R, Perret C. N-acetylcysteine enhances recovery from acute lung injury in man. A randomised, doubleblind, placebo-controlled clinical study. Chest 1994; 105 : 190-194.

245. Spapen H, Zhang H, Demanet C, Vleminckx W, Vincent JL, Huyghens L. Does $N$-acetyl-L-cysteine influence 
cytokine response during early human septic shock? Chest 1998; 113: 1616-1624.

246. Kharazmi A, Nielson H, Schiotz PO. $N$-acetylcysteine inhibits human neutrophil and monocyte chemotaxis and oxidative metabolism. Int J Immunopharmacol 1988; 10: 39-46.

247. van Klaveren RJ, Dinsdale D, Pype JL, Demedts M, Nemery B. $N$-acetylcysteine does not protect against type II cell injury after prolonged exposure to hyperoxia in rats. Am J Physiol 1997; 273: L548-L555.

248. Gillissen A, Jaworska M, Orth M, et al. $N$-acystelyn, a novel lysine salt of $N$-acetylcysteine, to augment cellular antioxidant defence in vitro. Respir Med 1997; 91: 159168.

249. Nagy AM, Vanderbist F, Parij N, Maes P, Fondu P, Neve $\mathrm{J}$. Effect of the mucoactive drug $N$-acystelyn on the respiratory burst of human blood polymorphonuclear neutrophils. Pulm Pharmacol Ther 1997; 10: 287-292.

250. Nishida K, Ohta Y, Ishiguro I. $\gamma$-glutamylcysteinyl ethylester attenuates progression of carbon tetrachloride-induced acute liver injury in mice. Toxicology 1998; 126: $55-63$.

251. Williamson JM, Boettcher B, Meister A. An intracellular cysteine delivery system that protects against toxicity by promoting glutathione synthesis. Proc Natl Acad Sci USA 1982; 79: 6246-6249.

252. Smith LJ, Anderson J, Shamsuddin M. Glutathione localisation and distribution after intratracheal instillation. Am Rev Respir Dis 1992; 145: 153-159.

253. Borok Z, Buhl R, Grimes GJ, et al. Effect of glutathione aerosol on oxidant-antioxidant imbalance in idiopathic pulmonary fibrosis. Lancet 1991; 338: 215-216.

254. Marrades RM, Roca J, Barbera A, Jover L, MacNee W, Rodriguiez-Roisin R. Nebulised glutathione induces bronchoconstriction in patients with mild asthma. $A m J$ Respir Crit Care Med 1997; 156: 425-430.

255. Buhl R, Vogelmeier C, Critenden M, et al. Augmentation of glutathione in the fluid lining the epithelium of the lower respiratory tract by directly administering glutathione aerosol. Proc Natl Acad Sci USA 1990; 87: 40634067.
256. Roum JH, Borok Z, McElvaney NG, et al. Glutathione aerosol suppresses lung epithelial surface inflammatory cell derived oxidants in cystic fibrosis. $J$ Appl Physiol 1999; 87: 438-443.

257. Hagen TM, Wierzbicka GT, Bowman BB, Aw TY, Jones DP. Fate of dietary glutathione: disposition in the gas-trointestinal tract. Am J Physiol 1990; 259: G530G535.

258. Holroyd KJ, Buhl R, Borok Z, et al. Correction of glutathione deficiency in the lower respiratory tract of HIV seropositive individuals by glutathione aerosol treatment. Thorax 1993; 48: 985-989.

259. Wernerman J, Hammarqvist F. Modulation of endogenous glutathione availability. Curr Opin Clin Nutr Metab Care 1999; 2: 487-492.

260. Jurima-Romet M, Shek PN. Lung uptake of liposomeentrapped glutathione after intratracheal adminstration. $J$ Pharm Pharmacol 1991; 43: 6-10.

261. Pena LR, Hill DB, McClain CJ. Treatment with glutathione precursor decreases cytokine activity. JPEN J Parenter Enteral Nutr 1999; 23: 1-6.

262. Gao L, Kim KJ, Yankaskas JR, Forman HJ. Abnormal glutathione transport in cystic fibrosis airway epithelia. Am J Physiol 1999; 277: L113-L118.

263. Linsdell P, Hanrahan JW. Glutathione permeability of CFTR. Am J Physiol 1998; 275: C323-C326.

264. Mulcahy RT, Bailey HH, Gipp JJ. Transfection of complementary DNAs for the heavy and light subunits of human $\gamma$-glutamylcysteine synthetase results in an elevation of intracellular glutathione and resistance to melphalan. Cancer Res 1995; 55: 4771-4775.

265. Manna SK, Kuo MT, Aggarwal BB. Overexpression of gammaglutamylcysteine synthetase suppresses tumor necrosis factor-induced apoptosis and activation of nuclear transcription factor-kappa B and activator protein-1. Oncogene 1999; 18: 4371-4382.

266. Hammarqvist F, Luo JL, Cotgreave IA, Andersson K, Wernerman J. Skeletal muscle glutathione is depleted in critically ill patients. Crit Care Med 1997; 25: 78-84. 